\title{
Taxifolin Alleviates Metabolic and Neurochemical Alterations in Hippocampus and Cortex of Brain of Rotenone-Toxified Rats in Vivo and Effectively Interacts with Enzymes Involve in Neurotransmission in Silico
}

\section{Sunday Solomon JOSIAH ( $\nabla$ ssjosiah@futa.edu.ng )}

Federal University of Technology Akure https://orcid.org/0000-0001-8126-358X

Ibrahim Olabayode Saliu

Federal University of Technology Akure

Haruna Isiyaku Umar

Federal University of Technology Akure

Courage Dele Famusiwa

Federal University of Technology Akure

Afolabi Clement Akinmoladun

Federal University of Technology Akure

\section{Research Article}

Keywords: Taxifolin, Neurotoxicity, Neurochemicals, Metabolic dysregulation, Complex I

Posted Date: July 13th, 2021

DOl: https://doi.org/10.21203/rs.3.rs-514482/v1

License: (1) This work is licensed under a Creative Commons Attribution 4.0 International License. Read Full License 


\section{Abstract}

Rotenone is a naturally occurring compound and inhibitor of mitochondrial complex I. Its exposure is toxic and directly affects the function of mitochondrial which leads to neurodegeneration. Taxifolin is a flavonoid that exhibits therapeutic potentials in various neurodegenerative diseases via its anti-oxidative, anti-inflammatory and neuromodulatory properties. In this study, we evaluated the therapeutic potential of taxifolin to alleviate metabolic and neurochemical alterations in the hippocampal and cortical region of brain of rotenone-toxified rats in vivo and to assess its influence on some enzymes involve in neurotransmission in silico. Taxifolin $(0.25,0.5$ and $1.0 \mathrm{mg} / \mathrm{kg})$ was orally post-administered to male Wistar rats for 3 days after 10 days subcutaneous administration of rotenone. Activities of mitochondrial complex I, membrane ion pump and lactate dehydrogenase (LDH) were evaluated in the hippocampus and cortex of the brain of rotenone-toxified rats. Markers of neurotransmitter metabolism and oxidative stress were also biochemically estimated and molecular interaction between taxifolin and tyrosine hydroxylase, monoamine oxidase, glutamine synthetase and $\mathrm{Na}^{+} \mathrm{K}^{+}$ATPase was determined by in silico simulation. Taxifolin attenuated dysfunction of mitochondrial, $\mathrm{Na}^{+} \mathrm{K}^{+}$ATPase, $\mathrm{LDH}$ and modulate neurotransmitter metabolism. Also, the elicited oxidative stress was mitigated by taxifolin in the hippocampus and cortex of the brain of rotenone-toxified rats. The highest binding affinity was recorded in taxifolin and tyrosine hydroxylase complex. Hydrogen bond and hydrophobic interactions were the two key molecular interaction between the taxifolin and targeted enzymes. Thus, taxifolin significantly exert therapeutic effect against rotenone-induced neurotoxicity in rats via anti-oxidative, as well as mitochondrial and neurotransmitter modulatory activity.

\section{Introduction}

Rotenone is a naturally occurring compound which can be employed as a broad spectrum organic pesticide. Also, it is a lipophilic compound that can readily cross cellular membrane after environmental exposure and cause a toxic effect to the brain (Yarmohammadi et al. 2020). Therefore, exposure to rotenone may lead to progressive deterioration of brain function that are characteristics of neurodegenerative diseases such as Alzheimer's disease (AD) and Parkinson's disease (PD) (Garabadu and Agrawal 2020). Consequently, rotenone neurotoxicity is reproduced into animal experimental model to mimic pathological features of PD since dopaminergic neuron of substantial nigra, among other neuronal cell types in other regions of the brain, are more susceptible to rotenone toxicity (Zhou et al. 2016). Asides the substantial nigra of striatal region of the brain, other regions that are prone to rotenone neurotoxicity includes the hippocampus and cortex and it may affects the functions of these brain regions (Sai et al. 2009; Zhou et al. 2016).

The primary toxicological effect of rotenone on brain cells (such as dopaminergic neuron and other cell types) is the inhibition of mitochondrial complex I activity which leads to overproduction of reactive oxygen species (ROS) and caused mitochondrial dysfunction (Tamilselvam et al. 2013). Mitochondrial is a very important sub-cellular organelle that plays a crucial role in modulating metabolic activity of brain cells such as ATP synthesis (Liu et al. 2005) and in promoting neuronal function, such as membrane ion 
pumps and channel activity and synaptic transmission (Sai et al. 2009). Dysfunction of the mitochondrial may leads to dysfunction of neurochemical (enzymes/protein) that may ultimately leads to death and degeneration of neuronal cells, resulting to functional deficits of the brain.

The development of drugs that are available for the management of neurotoxicity arising as a result of intolerant exposure to rotenone is faced with numerous side effects and are of limited benefit. Therefore, it is essential to establish an effective and alternative drug/therapy that could combat rotenone intoxication with minimal or no side effect. Natural compounds have been reported to have little or fewer side effect and also exhibit impressive pharmacological activities (Jia et al. 2018; Paunkov et al. 2019). Many studies have reported the potential therapeutic effect of natural compounds such as flavonoids, on brain injury through antioxidant and anti-inflammation (Anusha et al. 2017; Ma et al. 2018). The structural features of flavonoids such as $\mathrm{C}_{2}$ and $\mathrm{C}_{3}$ double bond, 4- carbonyl group, hydroxylation pattern, particularly the $3-\mathrm{OH}$ and ring $\mathrm{B}$ catechol moiety, has been attributed to their pharmacological properties (Wang et al. 2018).

Taxifolin (3,5,7,3,4-pentahydroxy flavanone or dihydroquercetin), a flavanone subclass of flavonoids, which are mostly found in citrus fruit. The double bond between carbon 2 and 3 of the $\mathrm{C}$-ring in the structural of taxifolin is saturated (Fig. 1). It has been reported that taxifolin promote the expression of phase II antioxidant and detoxifying enzymes and present a defensive role to the cell against DNA oxidative damage (Liang et al. 2013). Taxifolin has also been reported to present its anti-inflammatory effect by scavenging myeloperoxidase (MPO)-derived reactive nitrogen species (RNS) and showed inhibitory action against the excess production of reactive oxygen species (ROS) during brain injury (Weidmann 2012; Razak et al. 2018). Though, the bioactivity of flavonoids against neurological disease has been mostly attributed to their classical antioxidant effect, there are evidences that they also act by modulating neurotransmitter and mitigate mitochondrial dysfunction, control of neuronal signaling pathways, as well as interacting with inflammatory mediators and chelating transition metal. Hence, this study is designed to evaluate the neurotherapeutic potential of taxifolin to relieve metabolic and neurochemical alterations in the hippocampal and cortical region of brain of rotenone-toxified rats in vivo and its interaction with certain enzymes involve in neurotransmission in silico.

\section{Material And Methods}

\subsection{Chemicals and reagents}

Rotenone (R8875-1G), ( \pm )-taxifolin (3,5,7,3,4-pentahydroxy flavanone hydrate; T4512-25MG), thiobarbituric acid (TBA; T5500-25G), trichloroacetic acid (TCA), reduced glutathione (GSH; G4251), glutamic acid (49621-250G), adenosine triphosphate (ATP; A26209-1G), 6,7-Dimethyl-5,6,7,8tetrahydropterine (DMTHP; D0387-100MG), 5',5'-dithiobis-(2-nitrobenzoic acid) (DTNB; D218200-1G), perchloric acid (PCA; 1.09065), benzylamine hydrochloride (BAHC; B5136-25G), xanthine (X7375-10G), dopamine hydrochloride (H8502-5G), reduced nicotinamide-dinucleotide (NADH; N7004-25MG), ethylenediaminetetraacetic acid (EDTA; 03620-250G), 8-anilino-1-naphthalene sulfonic acid (ANSA; 
A1028-5G), 2,4-dinitrophenyl hydrazine (DNPH; D199303-25G), acetylcholine iodide (A7000-5G), coenzyme Q10 (C9538-100MG), a-ketoglutarate (75892-25G), epinephrine (E4250-1G),

tetramethylbenzidine (TMB; T19607-100G), L-Tyrosine (T3754), Bradford reagent (B6916-500ML), bovine serum albumin (BSA) and ammonium molybdate (A7302-100G) were all obtained from Sigma-Aldrich (St. Louis, MO, USA). All other chemicals and reagents used were of analytical grade.

\subsection{Animal grouping and treatment}

Male Wistar rats $(200 \pm 30 \mathrm{~g})$ were housed in the Animal House of the Department of Biochemistry, the Federal University of Technology Akure, Nigeria. They were fed with standard rat chow and water ad libitum. Animals were handled and used following the National Institute of Health, NIH, Guide for the Care and Use of Laboratory Animals, 2011. The experiments were approved by the institutional Committee for the Ethical Use of Research Animals of the Federal University of Technology, Akure (Ethical approval No: FUTA/ETH/2020/013). Animals were randomly assigned to the vehicle or treatment group.

The sample size of the animals used for the in vivo experiment was calculated as described by Yamane (1967). For the animal grouping, we assumed a total population of 71 rats and we calculated the sample size from the assumed population of the rats as follows;

$$
\mathrm{n}=\frac{N}{1+N\left(e^{2}\right)}
$$

Where; $\mathrm{n}=$ sample size, $\mathrm{N}=$ the population of study, and $\mathrm{e}=$ the accepted sampling error (i.e. \pm 0.05$)$. So, the sample size is calculated thus:

$$
\begin{aligned}
& \mathrm{n}=\frac{71}{1+71\left(0.05^{2}\right)} \\
& \mathrm{n}=\frac{71}{1+0.1775} \\
& \mathrm{n}=\frac{71}{1.1775}
\end{aligned}
$$

$\mathrm{n}=60.29 \approx 60$ rats in total for the in vivo experiment.

The sixty (60) rats were then divided into five groups with 12 animals per group. Group I: rats received the vehicle (corn oil) only (control); Group II: rats were subcutaneously administered rotenone (Rotenone); Groups III-V: rats were subcutaneously administered rotenone and thereafter post-treated with taxifolin (ROT + TAX $(0.25,0.5,1.0 \mathrm{mg} / \mathrm{kg}))$. Rotenone $(1.5 \mathrm{mg} / \mathrm{kg})$ was subcutaneously administered for 10 days, followed by post-treatment with varying doses of the taxifolin for 3 days through the same route (Akinmoladun et al. 2018; Thiffault et al. 2000). The doses of taxifolin used in this study were based on other study and on the preliminary study in our laboratory (Arutyunyan et al. 2013; Akinmoladun et al. 2018). 
After the last day of treatment, the animals were sacrificed by intraperitoneal injection with overdose of chloral hydrate $(400 \mathrm{mg} / \mathrm{kg})$ anesthesia and their brain was excised, rinsed in ice cold $1.15 \%(\mathrm{w} / \mathrm{v})$ potassium chloride solution, blotted with filter paper and weighed. The hippocampus and cortex of the brain were separated and processed for biochemical estimation. The hippocampus and cortex of the

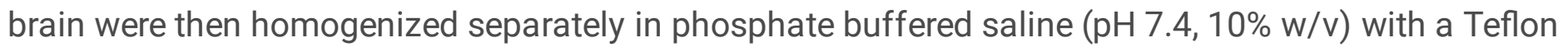
homogenizer and centrifuged at $10,000 \mathrm{~g}$ for 25 minutes at $4^{\circ} \mathrm{C}$ to obtain the supernatants (test sample) which were used for biochemical analyses. The method of Bradford (1976) was followed to determine the concentration of protein in the test sample.

\subsection{Biochemical estimation}

\subsubsection{Estimation of mitochondrial and neurochemical dysfunction markers in the hippocampus and cortex}

NADH oxidoreductase (complex I) activity in the test sample was estimated by a previously described method (Birch-Machin et al. 1994). Evaluation of $\mathrm{Na}^{+} / \mathrm{K}^{+}$-ATPase activity was carried out using previously described method (Svoboda and Mosinger 1981). Lactate dehydrogenase (LDH) activity was evaluated by a previously described method (Tienhaara and Meany 1973).

\subsubsection{Estimation of neurotransmitter metabolism in the hippocampus and cortex}

\subsubsection{Evaluation of dopamine metabolism}

The activity of tyrosine hydroxylase (TH) in the test sample was estimated according to the method of Craine et al. (1972). Monoamine oxidase (MAO) activity was evaluated by a previously described method (Chaudhary and Parvez 2012). Dopamine (DA) concentration in the test sample was determined by the method described by Guo et al. (2009).

\subsubsection{Evaluation of acetylcholinesterase activity (acetylcholine metabolism)}

Acetylcholinesterase (AChE) activity was evaluated using the method of Ellman et al. (1961). AChE activity was expressed in $\mu \mathrm{mol}$ of thiocholine produced $\mathrm{min}^{-1} \mathrm{mg}$ protein ${ }^{-1}$.

\subsubsection{Evaluation of glutamate metabolism}

Glutamine synthetase (GS) activity was evaluated as previously described by Stanimirovic et al. (1999) and the activity of glutamate dehydrogenase $(\mathrm{GDH})$ was evaluated by the method of Abdel-Zaher et al. (2011).

\subsubsection{Evaluation of oxidative stress in the hippocampus and cortex}


The method of Beutler et al. (1985) was followed to determine the level of reduced glutathione (GSH). Glutathione peroxidase (GPx) activity was estimated according to the method of Haque et al. (2003). The activity of superoxide dismutase (SOD) was evaluated by the method of Kakkar et al. (1984). Catalase (CAT) activity was evaluated according to the method of Clairborne (1985). Ferric reducing antioxidant power (FRAP) was determined using the method of Benzie and Strain (1996). The extent of lipid peroxidation was determined by measuring the formation of thiobarbituric acid reactive substances (TBARS) according to the method described by Varshney and Kale (1990). Protein carbonyl (PC) content was determined using to the method of Levine et al. (1990). Evaluation of xanthine oxidase (XO) activity was performed according to the method of Prajda and Weber (1975). Determination of nitrite level was carried out using Griess reaction (Guevara et al. 1998). The determination of total protein concentration was carried out using the method described by Bradford (1976).

\subsubsection{Evaluation of myeloperoxidase (MPO) activity in the hippocampus and cortex}

Assessment of Myeloperoxidase (MPO) activity was carried out according to the method of Eiserich et al. (1998). MPO activity is defined as the quantity of enzyme degrading one $\mu \mathrm{mol}$ peroxide $\mathrm{min}^{-1}$ and was expressed in units per mg protein.

\subsection{Molecular docking of taxifolin with target enzymes in silico}

Three dimensional (3D) structure of the ligand, taxifolin (CID: 439533), was obtained from PubChem NCBI database (https://www.ncbi.nlm.nih.gov/pubmed/) in simple file format (SDF), while the 3D X-ray crystal structures of our target receptors namely; TH, MAO, GS and $\mathrm{Na}^{+} / \mathrm{K}^{+}$-ATPase were acquired from the Protein Data Bank (PDB) of RCSB server with PDB identities of 2Z5X (Son et al. 2008), 2XSN (Parveen et al. 2016), 20JW (Krajewski et al. 2008) and 2ZXE (Shinoda et al. 2009), respectively. Taxifolin was loaded onto Open Babel segment of Python Prescription suite and were minimized using Merk Molecular Force Field 94 (MMF94). The target enzymes were then prepared for docking by selecting the General Amber Force Field 2 implemented in Cresset Flare@ software, version 4.0 (https://www.cressetgroup.com/flare/). Auto Dock Vina (Trott and Olson 2010) was employed to execute the docking steps using a flexible docking protocol. Grid box was set for each targets' active site as shown in Table 1. Thereafter, taxifolin was docked into the active domain of all the enzymes after which 10 binding postures for ligand-protein complex was made. The binding energy of taxifolin with corresponding enzyme targets was documented. The ligand-protein complex with the molecular interaction was prepared with PyMOL@ Molecular Graphics 2.4 (Shrodinger LLC) and was visualized in 3D and 2D using PyMOL@ Molecular Graphics and LigPlot ${ }^{+}$ver. 1.4.5. 
Table 1

The three-dimensional affinity grid parameters for geometric centre of each targeted enzyme and their dimension

\begin{tabular}{|llllll|}
\hline Parameters & Axis & TH & MAO & GS & Na $^{+} / \mathrm{K}^{+}$-ATPase \\
\hline Centre $(\AA)$ & $\mathrm{X}$ & 58.5225 & 42.2213 & 20.1623 & 143.4398 \\
& $\mathrm{Y}$ & 4.8750 & 28.1602 & -11.2307 & 18.7527 \\
& $\mathrm{Z}$ & 25.3225 & -15.3620 & -32.1268 & -5.8495 \\
\hline Dimension $(\AA)$ & $\mathrm{X}$ & 20.5642 & 33.0735 & 22.4927 & 25.9128 \\
\cline { 2 - 6 } & $\mathrm{Y}$ & 19.9405 & 25.000 & 27.0127 & 29.8543 \\
\cline { 2 - 5 } & $\mathrm{Z}$ & 22.5279 & 24.1228 & 31.6932 & 52.6109 \\
\hline MAO: monoamine oxidase; $\mathrm{TH}:$ Tyrosine hydrolase; GS: Glutamine synthetase \\
\hline
\end{tabular}

\subsection{Statistical analysis}

Statistical data were analyzed with SPSS 25.0 software (SPSS, Armonk, NY, USA) and graphs were drawn with graphics were drawn with Graphpad Prism 6.01 (GraphPad Software, Inc., USA). Quantitative data are expressed as the mean \pm standard deviation (SD). Kolmogorov-Smirnov tests were performed to test normality. Levene's test was used to assess the homogeneity of variance. Differences among multiple groups were analyzed by one-way ANOVA with the post hoc Tukey test when the assumptions of normality and homogeneity of variance were met or, if heterogeneity of variance was detected, by the Kruskal-Walli non-parametric analysis of variance followed by Tamhane's test for multiple comparisons between the assays (Table 2). The tests for normality and variance heterogeneity and other relevant statistical information are highlighted in the supplementary material. In all tests, $p<0.05$ was taken as a criterion for statistical significance. 
Table 2

Test Statistic outputs by One Way Analysis of Variance with all pairwise multiple comparison procedures done via Tukey Test

\begin{tabular}{|c|c|c|c|c|c|c|}
\hline & Cortex & & & Hippocampus & & \\
\hline $\begin{array}{l}\text { In vivo } \\
\text { Assays }\end{array}$ & $F(D F n, D F d)$ & $\begin{array}{l}P \\
\text { value }\end{array}$ & $\begin{array}{l}\mathrm{R} \\
\text { square }\end{array}$ & $\mathrm{F}(\mathrm{DFn}, \mathrm{DFd})$ & P value & $\begin{array}{l}\mathrm{R} \\
\text { square }\end{array}$ \\
\hline Complex I & $\begin{array}{l}F(10,121)= \\
620.2\end{array}$ & $\begin{array}{l}P< \\
0.0001\end{array}$ & 0.9809 & $F(10,121)=487.3$ & $\begin{array}{l}P< \\
0.0001\end{array}$ & 0.9758 \\
\hline $\begin{array}{l}\mathrm{Na}^{+} / \mathrm{K}^{+} \\
\text {ATPase }\end{array}$ & $\begin{array}{l}F(10,121)= \\
1059\end{array}$ & $\begin{array}{l}P< \\
0.0001\end{array}$ & 0.9887 & $F(10,121)=831.6$ & $\begin{array}{l}P< \\
0.0001\end{array}$ & 0.9857 \\
\hline LDH & $\begin{array}{l}F(10,121)= \\
561.7\end{array}$ & $\begin{array}{l}P< \\
0.0001\end{array}$ & 0.9789 & $F(10,121)=140.1$ & $\begin{array}{l}P< \\
0.0001\end{array}$ & 0.9205 \\
\hline TH & $\begin{array}{l}F(10,121)= \\
510.3\end{array}$ & $\begin{array}{l}P< \\
0.0001\end{array}$ & 0.9768 & $F(10,121)=1090$ & $\begin{array}{l}P< \\
0.0001\end{array}$ & 0.9890 \\
\hline MAO & $\begin{array}{l}F(10,121)= \\
443.0\end{array}$ & $\begin{array}{l}P< \\
0.0001\end{array}$ & 0.9734 & $F(10,121)=272.6$ & $\begin{array}{l}P< \\
0.0001\end{array}$ & 0.9575 \\
\hline DOP & $\begin{array}{l}F(10,121)= \\
229.7\end{array}$ & $\begin{array}{l}P< \\
0.0001\end{array}$ & 0.9500 & $F(10,121)=68.08$ & $\begin{array}{l}P< \\
0.0001\end{array}$ & 0.8491 \\
\hline AChE & $\begin{array}{l}F(10,121)= \\
392.4\end{array}$ & $\begin{array}{l}\mathrm{P}< \\
0.0001\end{array}$ & 0.9701 & $F(10,121)=755.1$ & $\begin{array}{l}P< \\
0.0001\end{array}$ & 0.9842 \\
\hline GDH & $\begin{array}{l}F(10,121)= \\
346.4\end{array}$ & $\begin{array}{l}P< \\
0.0001\end{array}$ & 0.9662 & $F(10,121)=738.6$ & $\begin{array}{l}P< \\
0.0001\end{array}$ & 0.9839 \\
\hline GS & $\begin{array}{l}F(10,121)= \\
346.4\end{array}$ & $\begin{array}{l}P< \\
0.0001\end{array}$ & 0.9892 & $F(10,121)=1112$ & $\begin{array}{l}P< \\
0.0001\end{array}$ & 0.9839 \\
\hline GSH & $\begin{array}{l}F(10,121)= \\
395.4\end{array}$ & $\begin{array}{l}P< \\
0.0001\end{array}$ & 0.9703 & $F(10,121)=358.9$ & $\begin{array}{l}P< \\
0.0001\end{array}$ & 0.9674 \\
\hline GPx & $\begin{array}{l}F(10,121)= \\
491.7\end{array}$ & $\begin{array}{l}P< \\
0.0001\end{array}$ & 0.9760 & $F(10,121)=385.3$ & $\begin{array}{l}P< \\
0.0001\end{array}$ & 0.9696 \\
\hline SOD & $\begin{array}{l}F(10,121)= \\
155.9\end{array}$ & $\begin{array}{l}P< \\
0.0001\end{array}$ & 0.9280 & $F(10,121)=1217$ & $\begin{array}{l}P< \\
0.0001\end{array}$ & 0.9902 \\
\hline CAT & $\begin{array}{l}F(10,121)= \\
2829\end{array}$ & $\begin{array}{l}P< \\
0.0001\end{array}$ & 0.9957 & $F(10,121)=4235$ & $\begin{array}{l}P< \\
0.0001\end{array}$ & 0.9972 \\
\hline FRAP & $\begin{array}{l}F(10,121)= \\
562.8\end{array}$ & $\begin{array}{l}\mathrm{P}< \\
0.0001\end{array}$ & 0.9790 & $F(10,121)=357.5$ & $\begin{array}{l}\mathrm{P}< \\
0.0001\end{array}$ & 0.9673 \\
\hline
\end{tabular}

Complex I: NADH:Ubiquinone oxidoreductase activity; LDH: Lactate dehydrogenase; TH: Tyrosine hydroxylase; MAO: Monoamine oxidase; DOP: Dopamine; AChE: Acetylcholinesterase; GDH: Glutamate dehydrogenase; GS: Glutamine synthetase; GSH: Reduced glutathione; GPx: Glutathione peroxidase; SOD: Superoxide dismutase; CAT: Catalase; FRAP: Ferric reducing antioxidant power; Protein carbonyl; LPO: Lipid peroxidation (TBARS); NO: Nitric oxide level; XO: Xanthine oxidase activities/levels. 


\begin{tabular}{|c|c|c|c|c|c|c|}
\hline & Cortex & & & Hippocampus & & \\
\hline PC & $\begin{array}{l}F(10,121)= \\
164.7\end{array}$ & $\begin{array}{l}\mathrm{P}< \\
0.0001\end{array}$ & 0.9315 & $F(10,121)=201.8$ & $\begin{array}{l}\mathrm{P}< \\
0.0001\end{array}$ & 0.9434 \\
\hline LPO & $\begin{array}{l}F(10,121)= \\
292.1\end{array}$ & $\begin{array}{l}P< \\
0.0001\end{array}$ & 0.9602 & $F(10,121)=96.48$ & $\begin{array}{l}P< \\
0.0001\end{array}$ & 0.8886 \\
\hline NO & $\begin{array}{l}F(10,121)= \\
465.7\end{array}$ & $\begin{array}{l}\mathrm{P}< \\
0.0001\end{array}$ & 0.9747 & $F(10,121)=469.8$ & $\begin{array}{l}P< \\
0.0001\end{array}$ & 0.9817 \\
\hline XO & $\begin{array}{l}F(10,121)= \\
1545\end{array}$ & $\begin{array}{l}P< \\
0.0001\end{array}$ & 0.9922 & $\begin{array}{l}F(10,121)=3.575 e+ \\
029\end{array}$ & $\begin{array}{l}P< \\
0.0001\end{array}$ & 1.0000 \\
\hline MPO & $\begin{array}{l}F(10,121)= \\
680.0\end{array}$ & $\begin{array}{l}P< \\
0.0001\end{array}$ & 0.9825 & $F(10,121)=173.4$ & $\begin{array}{l}P< \\
0.0001\end{array}$ & 0.9348 \\
\hline \multicolumn{7}{|c|}{$\begin{array}{l}\text { Complex I: NADH:Ubiquinone oxidoreductase activity; LDH: Lactate dehydrogenase; TH: Tyrosine } \\
\text { hydroxylase; MAO: Monoamine oxidase; DOP: Dopamine; AChE: Acetylcholinesterase; GDH: } \\
\text { Glutamate dehydrogenase; GS: Glutamine synthetase; GSH: Reduced glutathione; GPX: Glutathione } \\
\text { peroxidase; SOD: Superoxide dismutase; CAT: Catalase; FRAP: Ferric reducing antioxidant power; } \\
\text { Protein carbonyl; LPO: Lipid peroxidation (TBARS); NO: Nitric oxide level; XO: Xanthine oxidase } \\
\text { activities/levels. }\end{array}$} \\
\hline
\end{tabular}

\section{Result}

This study is on in vivo biochemical and in silico simulation and a blind experimenter is not needed for the experiment. The analysis of the results are not influenced by the experimenter.

\subsection{Taxifolin assuaged hippocampal and cortical mitochondrial and neurochemical dysfunction in rotenone- toxified rats}

Rotenone is a mitochondrial complex I blocker that has an effect on neuronal excitability and the rate of glucose catabolism. The benefit of taxifolin to alleviate this anomaly in the hippocampus and cortex of rotenone-toxified rats was therefore evaluated in this study.

Figure 2(a-c) showed the effect of taxifolin in reducing mitochondrial and neurochemical dysfunction in hippocampus and cortex of brain of rats occasioned by rotenone intoxication. Rotenone intoxication caused a significant reduction $(p<0.0001)$ of complex 1 activity which indicates mitochondrial damage. Hippocampus and cortex of rats post-treated with taxifolin at all doses showed significant increase $(p<$ 0.0001 ) in complex I activity (Fig. 2a). Figure $2 b$ showed a significant decrease $(p<0.0001)$ in the hippocampal and cortical $\mathrm{Na}^{+} / \mathrm{K}^{+}$ATPase activity of rat intoxicated with rotenone compared to control. Rats treated with taxifolin showed increased activity $(p<0.0001)$ of $\mathrm{Na}^{+} / \mathrm{K}^{+}$ATPase compared to rotenone-toxified rats. In Fig. 2c, LDH activity of rats intoxicated with rotenone increases compared to the 
control rats signifying lactic acid build up. LDH activity significantly decreased $(p<0.0001)$ in rats posttreated with taxifolin signifying reduced acidosis compared to rotenone-toxified rats without treatment.

\subsection{Neurotransmitter dysregulation in rotenone-toxified rats was ameliorated by taxifolin}

Neurotransmitter dysregulation was carried out to check the involvement of glutaminergic, cholinergic and dopaminergic system in the hippocampus and cortex of rats subjected to rotenone neurotoxicity and the therapeutic effect of taxifolin to correct the dysfunction in neurotransmitters was assessed. Rotenone intoxication caused hippocampal and cortical dysregulation in dopamine (Fig. 3a-c), acetylcholine (Fig. 4) and glutamine metabolism (Fig. 5a-b) in the brain of rats.

There is significant decrease $(p<0.0001)$ in TH activity in rotenone-toxified rats compared to control which indicate reduced formation of L-DOPA (Fig. 3a). Also, MAO activity significantly decreased (Fig. 3b) with a concomitant reduction $(p<0.05)$ in dopamine level (Fig. 3c) in the brain of rotenone-toxified rats compared to control. This anomaly in dopamine metabolism was significantly mitigated $(p<0.0001)$ by taxifolin post-treatment at all doses, except $0.25 \mathrm{mg} / \mathrm{kg}$ taxifolin treatment at the cortical region which did not have effect on MAO activity.

Figure 4 showed a significant decrease $(p<0.0001)$ in AChE activity in the hippocampus and cortical region of brain of rotenone-toxified rats compared to the control. Rotenone-toxified rats post-treated with taxifolin showed a significant increase $(p<0.0001)$ in AChE activity. As shown in Fig. 4, post treatment with taxifolin has more effect on the hippocampus than the cortex.

Rotenone intoxication caused significant decrease ( $p<0.0001)$ in GDH (Fig. 5a) and GS (Fig. 5b) activity compared with the control. This indicates that glutamate level increased in the cell and this can result in excitotoxicity. Rats treated with taxifolin showed a significant increase $(p<0.0001)$ in the activity of GDH and GS compared with untreated rats.

\subsection{Taxifolin ameliorated oxidative stress in hippocampus and cortex of brain of rotenone-toxified rats}

Oxidative stress is one of the main pathophysiological events implicated in rotenone neurotoxicity and pharmacological intervention that assuage oxidative stress could be considered a potential therapy. Hence, the effect of taxifolin to reduce oxidative stress was evaluated.

Oxidative stress elicited by rotenone administration in the hippocampus and cortex was mitigated by taxifolin post-treatment and is presented in Fig. $6(a-i)$. Taxifolin significantly ameliorated $(p<0.0001)$ the decreased level of GSH (Fig. 6a), and activity of antioxidant enzyme, GPx (Fig. 6b), SOD (Fig. 6c) and catalase (Fig. 6d), as well as reduced the level of FRAP (Fig. 6e) in hippocampus and cortex of rotenonetoxified rats. Rotenone intoxication caused increase in protein carbonylation (Fig. 6f) and lipid peroxidation was evoked (Fig. $6 \mathrm{~g})$, these were significantly abated $(\mathrm{p}<0.05)$ by taxifolin post-treatment at all doses. Rotenone-toxified rats showed significant increase $(p<0.0001)$ in the level of nitric oxide 
(Fig. 6h) and activity of xanthine oxidase (Fig. 6i) compared to control and were significantly reduced ( $\mathrm{p}<$ 0.0001 ) by taxifolin post-treatment at all doses

\subsection{MPO activity in rotenone-toxified rats was assuaged by taxifolin post-treatment}

Inflammation is a key event in rotenone neurotoxicity and the ability of taxifolin to mitigate the initiation of inflammatory event was determined by evaluating the activity of MPO. Figure 7 showed a significant increase $(p<0.0001)$ in MPO activity in rotenone-toxified rats compared to control, which is indicative of inflammatory events. Taxifolin post-treatment at all doses caused a significant decrease $(p<0.0001)$ in the activity of MPO compared to untreated rats.

For the in vivo experiments, the test statistics of the One Way Analysis of Variance with all pairwise multiple comparison procedures done via Tukey Test were presented in Table 2.

\subsection{Binding affinity and molecular interactions between taxifolin and targeted neurochemical enzymes}

The involvement of TH, MAO, GS, as well as $\mathrm{Na}^{+} / \mathrm{K}^{+}-\mathrm{ATPase}$ in neurotransmission is a reflective of the importance of neurotransmitter and neuronal membrane potential. In silico simulation was employed to check the interaction between these enzymes and taxifolin so as to ratify the pharmacological effect of taxifolin in abating neurotoxicity.

The in silico inhibitory mechanisms of taxifolin alongside some selected key enzymes implicated in neurotoxicity was evaluated through molecular docking. Molecular docking simulation showed that taxifolin modulated targeted enzymes in silico. Taxifolin showed a good binding affinity with targeted enzymes (Table 3). Taxifolin has the highest binding energy with TH $(-9.8 \mathrm{kcal} / \mathrm{mol})$, followed by GS $(-9.0$ $\mathrm{kcal} / \mathrm{mol})$. $\mathrm{Na}^{+} / \mathrm{K}^{+}$-ATPase showed the lowest binding energy with taxifolin $(-7.7 \mathrm{kcal} / \mathrm{mol})$. This implies that taxifolin enhance the activity of TH and GS than the enzymes with low binding energy. Also, Table 3 showed the analysis of docking conformation and the important amino acid residue participating in molecular interaction in the complexes formed between our targeted enzyme and taxifolin. This indicated that hydrogen bond and hydrophobic interactions are the obvious intermolecular forces in these complexes (Fig. 8a-d). 
Table 3

Binding affinity scores and molecular interaction analysis of taxifolin (Tax) docked against acetylcholinesterase (AChE), monoamine oxidase (MAO), Glutamine synthetase (GS), Tyrosine hydroxylase $(\mathrm{TH})$ and $\mathrm{Na}^{+} / \mathrm{K}^{+}$-ATPase

\begin{tabular}{|c|c|c|c|c|c|}
\hline $\begin{array}{l}\text { Ligand- } \\
\text { Protein } \\
\text { Complexes }\end{array}$ & $\begin{array}{l}\text { Binding } \\
\text { Affinity } \\
\text { (kcal/mol) }\end{array}$ & $\begin{array}{l}\text { Residues } \\
\text { forming } \\
\text { H-bonds }\end{array}$ & $\begin{array}{l}\text { Residues } \\
\text { involved in } \mathrm{H}- \\
\text { bonds formation }\end{array}$ & $\begin{array}{l}\text { Distances } \\
(\AA)\end{array}$ & $\begin{array}{l}\text { Hydrophobic interacting } \\
\text { residues }\end{array}$ \\
\hline Tax-TH & -9.8 & 1 & Asp 455 & 2.98 & $\begin{array}{l}\text { Phe 407, Pro 355, Pro } \\
\text { 357, Leu 324, Trp 402, } \\
\text { His 361, Phe } 330 \text { and } \\
\text { Tyr 401 }\end{array}$ \\
\hline Tax-MAO & -7.8 & 1 & Tyr 441 & 2.90 & $\begin{array}{l}\text { Gly } 67, \text { Tyr } 407 \text {, Phe } 352 \text {, } \\
\text { Ile 180, Gln } 215 \text {, Leu } \\
\text { 337, Phe 208, Met 350, } \\
\text { Ile } 335 \text { and Thr } 336\end{array}$ \\
\hline Tax-GS & -9.0 & 7 & $\begin{array}{l}\text { His 253, Arg 340, } \\
\text { Ser 320, Ala 321, } \\
\text { Arg 299, Asn } 248 \\
\text { and Lys } 241\end{array}$ & $\begin{array}{l}3.19(2.92) \\
2.77,3.13 \\
2.92,3.25 \\
2.97 \text { and } \\
2.89\end{array}$ & $\begin{array}{l}\text { Trp 247, Gly 249, Arg } \\
329 \text { and Ser } 307\end{array}$ \\
\hline $\begin{array}{l}\text { Tax- } \\
\mathrm{Na}^{+} / \mathrm{K}^{+}- \\
\text {ATPase }\end{array}$ & -7.7 & 4 & $\begin{array}{l}\text { Thr } 804, \text { Glu } 915, \\
\text { Lys } 912 \text { and Asp } \\
891\end{array}$ & $\begin{array}{l}3.10 \\
3.18(2.96) \\
2.80 \text { and } \\
2.76\end{array}$ & $\begin{array}{l}\text { Phe 790, Phe 793, lle } \\
322 \text {, Asn 129, lle 325, } \\
\text { Asp 128, Leu } 132 \text { and } \\
\text { Leu } 800\end{array}$ \\
\hline \multicolumn{6}{|c|}{$\begin{array}{l}\text { Tax-TH: Taxifolin-Tyrosine hydroxylase complex; Tax-MAO: Taxifolin-Monoamine oxidase complex; } \\
\text { Tax-GS: Taxifolin-Glutamine synthetase complex; Tax- } \mathrm{Na}^{+} / \mathrm{K}^{+} \text {-ATPase: Taxifolin- } \mathrm{Na}^{+} / \mathrm{K}^{+} \text {-ATPase }\end{array}$} \\
\hline
\end{tabular}

\section{Discussion}

In this study, taxifolin increased mitochondrial complex I and $\mathrm{Na}^{+} \mathrm{K}^{+}$ATPase activities, mitigated LDH activity and modulated neurotransmitter dysregulation. The oxidative stress evoked by rotenone intoxication was reduced by taxifolin in the hippocampus and cortex of the brain of rotenone-toxified rats. The involvement of hydrogen bond and hydrophobic interactions was notably documented as the two key molecular interaction between taxifolin and the targeted enzymes. The mechanism by which taxifolin exerted its therapeutic efficacy against rotenone neurotoxicity includes anti-oxidative, anti-inflammatory and, mitochondrial and neurotransmitter modulatory ability.

Polyphenols including taxifolin is able to perform their pharmacological and immunomodulatory activity due to their ability to donate electrons and hydrogen atoms by the functional groups in their structure (Procházková et al. 2011; Sandoval-Avila et al. 2019), for example, degree of hydroxylation of ring B and unsaturation degree of $\mathrm{C}_{2}$ and $\mathrm{C}_{3}$ double bond in the $\mathrm{C}$-ring, are two structural features attributed to their beneficial role in combating brain injury (Wang et al. 2018). The biological activities of phytochemicals 
has been demonstrated to depend upon their bio-accessibility and bioavailability in the brain in other to be an effective anti-inflammatory agent (Phan et al. 2018).

Rotenone, an inhibitor of complex I enzyme of the electron transport chain (ETC), has been reported to cause free-radical dependent oxidative injury and neurochemical dysfunction (Khadrawy et al. 2017). This study showed decrease in hippocampal and cortical complex I activity in rotenone-toxified rats. This results in mitochondrial dysfunction, caused bioenergetic defect and lead to cascade of pathologies that is ensued in rotenone neurotoxicity. The ameliorated activity of complex I by taxifolin in the present study may have a mitigating effect on other deleterious mechanism that rotenone intoxication may have elicited. $\mathrm{Na}^{+} \mathrm{K}^{+}$ATPase is responsible for the generation of neuronal membrane potential through active efflux of $\mathrm{Na}^{+}$and influx of $\mathrm{K}^{+}$in the neuron. $\mathrm{Na}^{+} \mathrm{K}^{+}$ATPase is an active enzyme that performs its activity through phosphorylation by ATP and thus, maintains neuronal excitability (de Lores Arnaiz and Ordieres 2014). Also, $\mathrm{Na}^{+} / \mathrm{K}^{+}$ATPase is implicated in metabolic energy production and in the uptake, storage, and metabolism of neurotransmitters (Carageorgiou et al. 2007). Therefore, dysfunction in the activity of complex I that results to insufficient generation of ATP attenuated the activity of $\mathrm{Na}^{+} \mathrm{K}^{+}$ATPase which was observed in the hippocampus and cortex of rotenone-toxified rats in this study.

Taxifolin was able to assuage this anomaly in rotenone-toxified rats. Furthermore, LDH activity has been employed as of cell membrane integrity indicator and to assess cell death in rotenone neurotoxicity (Elmazoglu et al. 2018). Incomplete oxidation of glucose is a metabolic consequence of complex I inhibition by rotenone and this subsequently caused lactic acid accumulation, as observed when LDH activity increased in this study. Mitochondrial dysfunction may consequently result to rotenone-induced cell death. In this study, hippocampal and cortical metabolic alterations as a consequence of rotenone intoxication was mitigated by taxifolin as revealed by decrease in LDH activity.

Dysregulation of dopamine metabolism was documented in the hippocampus and cortex region of brain in this study as a result of rotenone intoxication. Dysfunction of dopaminergic neuron or decrease in dopamine level causes motor (movement) disorder and depressive-like behavior of rats that are characteristics of neurodegenerative diseases. TH catalyzed the biosynthesis of L-DOPA (a precursor of dopamine) in a rate-limiting reaction in the brain. The level of L-DOPA is proportional to the concentration of dopamine availability in brain cells. Reports have demonstrated the role of $\mathrm{TH}$ in the pathogenesis of PD and other brain injury (Nakashima et al. 2013; Saliu et al. 2020). Also, dopamine can be deaminated by MAO to form catecholaldehyde and 3,4-dihydroxyphenylacetaldehyde, a cytotoxic intermediate which is can exacerbate neuronal injury (Goldstein et al. 2015).

In this study, taxifolin was able to alleviate dysfunction in dopamine metabolism, which result in increased dopamine bioavailability in the hippocampus and cortex of brain of rotenone-toxified rats. Acetylcholine is the main molecule in cholinergic system that is important in motor control and also, regulates cognitive functions. Neurotransmission in cholinergic system is terminated by AChE by hydrolyzing acetylcholine to actetate and choline. Decrease in AChE activity is observed in the hippocampus and cortex of the brain of rotenone-toxified rats in the present study and inhibition of AChE 
activity has been reported to aggravate motor dysfunction in rotenone neurotoxicity (Abdel-Salam et al. 2014). Increase in hippocampal and cortical AChE activity by taxifolin could assuage motor, cognitive and memory impairment induced by rotenone toxicity.

It has been reported that mitochondrial dysfunction and excitotoxicity play an important role in the pathogenesis of rotenone-induced neurotoxicity. The mitochondrial dysfunction is induced by the inhibition of mitochondrial complexes I and predisposes motor neurons to ionotropic glutamate receptormediated excitotoxicity which ultimately caused death of motor neuron (Kanki et al. 2004). Glutamate excitotoxicity was evident in rotenone-toxified rats in this study. In metabolizing cell, GDH metabolizes glutamate to a-ketoglutarate while GS caused amidation of glutamate to glutamine with simultaneous hydrolysis of ATP. Excess glutamate in the cell is biochemically recycled in this manner to prevent accumulation of neurotoxic glutamate (excitotoxicity). Taxifolin markedly modulates the activity of GS and GDH in the hippocampus and cortex of rotenone-induced neurotoxicity in the present study. The action of taxifolin to mitigate oxidative stress and alleviate mitochondrial dysfunction may also enhance the activity of GS and GDH to attenuate glutamate excitotoxicity in taxifolin post-treated rats.

Oxidative stress has been demonstrated as a major pathology in neurotoxicity induced by rotenone. In rodents, subcutaneous exposure to rotenone increase the generation of reactive oxygen species in many brain regions such as cortex, hippocampus and striatum (Abdel-Salam et al 2013; Farombi et al. 2019). Glutathione is an endogenous non-enzymic antioxidant, which in its reduced form (GSH) along with other antioxidants, scavenge free radicals and protects the cells from oxidative injury, as well as maintains reduced intracellular homeostasis. Superoxides are free radical oxygen species that are produced constantly by metabolizing cells, especially in the brain and could turn reactive species when it is overwhelmingly produced and then caused oxidative stress. Superoxide dismutase catalyses the dismutation of the superoxide radicals into water and hydrogen peroxide, a non-radical reactive oxygen species while the hydrogen peroxide is further reduced by GPx and catalase into water and oxygen (Garcia-Sánchez et al. 2020; Hasanuzzaman et al. 2020).

Oxidative stress generated during rotenone intoxication as observed in this study could arise from metabolic consequence of mitochondrial dysfunction and incomplete glucose oxidation. More hydrogen peroxide is also produced when purines are been broke down to uric acid in the cell by XO (Cristiana et al., 2014). The free radical produced leads to oxidative damage that caused protein carbonylation and consequently attacks membrane lipid.

Increment in NO level as seen in this study has been linked to altered neural development through reactive nitrogen species activation. Peroxynitrite, a potent oxidant, formed from the interaction between NO and superoxide modified proteins, lipids and DNA (Korhonen et al. 2005), this may be responsible for the increase in hippocampal and cortical protein carbonyl level and extent of lipid peroxidation, as well as increased NO level observed in this study. The abundance of polyunsaturated fatty acids, oxygen utilization, and high metabolic activity of the brain makes it susceptible to oxidative stress and a range of cellular dysfunctions (Akinmoladun et al., 2019). Also, oxidative stress can trigger the expression of 
molecules that are involved in inflammatory pathology (Hussain et al., 2016), which is evidently seen in increase activity of MPO in this study.

The neurotoxic effect of rotenone on generating oxidative stress in the hippocampal and cortical region were markedly attenuated by taxifolin via restoration of level and activity of antioxidants (enzymic and non-enzymic), reduction of $\mathrm{Fe}$ (III) to $\mathrm{Fe}$ (II), scavenge reactive oxygen and nitrogen species and decrease NO level with consequent reduction in protein carbonylation and lipid peroxidation. Our study corroborated with other studies that reported the neuroprotective effect of taxifolin against diseases via attenuating oxidative injury (Tanka et al. 2019; Inoue et al. 2019). Taxifolin has been demonstrated to have anti-inflammatory property by scavenging reactive nitrogen species claimed to have elicited increased MPO activity (Rasak et al. 2018).

In the present study, the targeted enzymes selected for molecular docking simulation are enzymes involved in metabolism of neurotransmitters (TH and MAO for dopamine metabolism and GS for glutamate metabolism) and maintenance of membrane ionic gradient ( $\left.\mathrm{Na}^{+} / \mathrm{K}^{+}-\mathrm{ATPase}\right)$. Dysfunction in the activity of these enzymes will cause dysregulation in neurotransmission and may ultimately leads to behavioral deficits. Interestingly, the binding energies from the molecular docking simulation in this study revealed that taxifolin effectively interacted with the targeted enzymes and thus modulated the activities of these enzymes. The non-covalent interactions (hydrogen bond and hydrophobic interaction) are the intermolecular forces that are crucial in the stability of ligand-protein complex (Ogunwa and Ayenitaju 2017; Stojanovi and Zari 2009) and also could be involved in the high binding energy values of the ligands (Mohapatra et al. 2015; Umar et al. 2020) observed in our current findings.

In conclusion, taxifolin exert therapeutic effect against metabolic and neurochemical modification in rotenone-induced neurotoxicity in rats via anti-oxidative, as well as mitochondrial and neurotransmitter modulatory activity, which is strongly supported by molecular docking and interaction of taxifolin with dopamine and glutamate metabolizing enzyme as well as $\mathrm{Na}^{+} / \mathrm{K}^{+}$-ATPase. Noteworthily, the potentiality of taxifolin to exhibit the therapeutic activity highlighted in this study is associated to its structural features, such as its catechol structure in the $B$ ring, saturated $C_{2}$ and $C_{3}$ bond in conjugation with a 4-oxo function in the $C$ ring provides electron delocalization from the $B$ ring and hydroxyl groups at positions 3 and 5 provides hydrogen bonding to the oxo group, thereby, cementing the notion of structure-function activity of flavonoids.

\section{Declarations}

\section{Acknowledgement}

The authors would like to thank Ms. F. A. Fadiji of Funmdek \& Co. Integrated Solution (fisolution@yahoo.com) for assisting with the SPSS statistical analysis.

\section{Funding}


The authors did not receive support from any organization for the submitted work.

\section{Competing interest}

The authors have no conflict of interest to declare that are relevant to the content of this article.

\section{Availability of data and material}

All data generated or analyzed during this study are included in this published article and are also available from the corresponding author on reasonable request.

\section{Code availability}

Not applicable

\section{Authors' contributions}

Sunday Solomon Josiah, Courage Dele Famusiwa and Afolabi Clement Akinmoladun contributed to conception and design of the study; Sunday Solomon Josiah and Courage Dele Famusiwa carried out the in vivo experiments; Haruna Isiyaku Umar carried out the in silico study; Sunday Solomon Josiah and Haruna Isiyaku Umar analyzed and/or interpreted the data; Sunday Solomon Josiah, Haruna Isiyaku Umar and Ibrahim Olabayode Saliu drafted the manuscript; Sunday Solomon Josiah and Ibrahim Olabayode Saliu revised the manuscript; Afolabi Clement Akinmoladun supervised the project. All the authors have read and approved the final manuscript before its submission.

\section{Ethical approval}

This experiment was approved by the animal research ethical committee of the Federal University of Technology, Akure with ethical approval number FUTA/ETH/2020/013. Animals were handled and used following the ethical principles established by the National Institute of Health Guide for the Care and Use of Laboratory Animals (National Institute of Health, NIH Publication No. 8523, 1978, revised 2011).

\section{Consent to participate}

Not applicable

\section{Consent for publication}

Not applicable

\section{References}

1. Abdel-Salam O, Omara E, Youness E, KhadrawyY, Mohammed N, Sleem A (2014) Rotenone-induced nigrostriatal toxicity is reduced by methylene blue. J Neurorestoratology 2014(2):65-80. https://doi.org/10.2147/jn.s49207 
2. Abdel-Zaher AO, Abdel-Rahman MS, Elwasei FM (2011) Protective effect of Nigella sativa oil against tramadol-induced tolerance and dependence in mice: role of nitric oxide and oxidative stress. NeuroToxicology 32:725-733. https://doi.org/10.1016/j.neuro.2011.08.001

3. Akinmoladun AC, Farombi TH, Farombi EO (2019) Food for Brain Health: Flavonoids. In L. Melton, F. Shahidi, O. Varelis (Eds.), Encyclopedia of Food Chemistry 3:370-386. Elsevier Inc. https://doi.org/10.1016/B978-0-08-100596-5.21752-6.

4. Akinmoladun AC, Oladejo CO, Josiah SS, Famusiwa CD, Ojo OB, Olaleye MT (2018) Catechin, quercetin and taxifolin improve redox and biochemical imbalances in rotenone-induced hepatocellular dysfunction: Relevance for therapy in pesticide-induced liver toxicity? Pathophysiology 25(4):365-371. https://doi.org/10.1016/j.pathophys.2018.07.002

5. Anusha C, Sumathi T, Joseph LD (2017) Protective role of apigenin on rotenone induced rat model of Parkinson's disease: Suppression of neuroinflammation and oxidative stress mediated apoptosis. Chem-Biol Interact 269:67-79. http://doi.org.10.1016/j.cbi.2017.03.016

6. Arutyunyan TV, Korystova AF, Kublik LN, Levitman MK, Shaposhnikova VV, Korystov YN (2013) Effects of taxifolin on the activity of angiotensin-converting enzyme and reactive oxygen and nitrogen species in the aorta of aging rats and rats treated with the nitric oxide synthase inhibitor and dexamethasone. Age 35(6): 2089-2097. http://dx.doi.org/10.1007/s11357-012-9497-4.

7. Benzie IF, Strain JJ (1996) The ferric reducing ability of plasma (FRAP) as a measure of antioxidant power: The FRAP Assay. Anal Biochem 239:70-76. https://doi.org/10.1006/abio.1996.0292

8. Beutler, E., Duwn, O., Kelly, B., 1985. Improved method for the determination of blood glutathione. J. Lab. Clin. Med. 61, 882-888

9. Birch-Machin MA, Briggs HL, Saborido AA, Bindoff LA, Turnbull DM (1994) An evaluation of the measurement of the activities of complexes I-IV in the respiratory chain of human skeletal muscle mitochondria. Biochem Med Metab Biol 51:35-42. https://doi.org/10.1006/bmmb.1994.1004

10. Bradford MM (1976) A rapid and sensitive method for the quantitation of microgram quantities of protein utilizing the principle of protein-dye binding. Anal Biochem 72:248-254. https://doi.org/10.1016/0003-2697(76)90527-3

11. Carageorgiou H, Pantos C, Zarros A, Stolakis V, Mourouzis I, Cokkinos D, Tsakiris S (2007) Changes in acetylcholinesterase, $\mathrm{Na}^{+} / \mathrm{K}^{+}$ATPase, and $\mathrm{Mg}^{2+}$ ATPase activities in the frontal cortex and the hippocampus of hyper and hypothyroid adult rats. Metab Brain Dis 22:31-38. https://doi.org/10.1016/j.metabol.2007.04.003

12. Chaudhary S, Parvez S (2012) An in vitro approach to assess the neurotoxicity of valproic acidinduced oxidative stress in cerebellum and cerebral cortex of young rats. J Neurosci 225:258-268. https://doi.org/10.1016/j.neuroscience.2012.08.060

13. Clairborne A (1985) Catalase Activity, in: Greenwald, R.A. (Ed.), CRC Handbook of Methods for Oxygen Radical Research. CRC Press, Boca Raton, Florida, USA pp 283-284

14. Craine JE, Hall ES, Kaufman S (1972) The isolation and characterization of dihydropteridine reductase from sheep liver. J Biol Chem 247:6082-6091. 
15. Cristiana, F., Elena, A., Nina, Z., 2014. Superoxide dismutase: therapeutic targets in SOD related pathology. Health 6(10):975-988. https://doi.org/10.4236/health.2014.610123

16. de Lores Arnaiz GR, Ordieres MG (2014) Brain Na(+), K(+)-ATPase activity in aging and disease. Int J Biomed Sci 10:85-102.

17. Eiserich JP, Hristova M, Cross CE, Jones AD, Freeman BA, Halliwell B, van der Vliet A (1998) Formation of nitric oxide-derived inflammatory oxidants by myeloperoxidase in neutrophils. Nature 391:393-397. https://doi.org/10.1038/34923

18. Ellman GL, Courtney KD, Andres V, Featherstone RM (1961) A new and rapid colorimetric determination of acetylcholinesterase activity. Biochem Pharmacol 7:88-95. https://doi.org/10.1016/0006-2952(61)90145-9

19. Elmazoglu Z, Yar Saglam AS, Sonmez C, Karasu C (2018) Luteolin protects microglia against rotenone-induced toxicity in a hormetic manner through targeting oxidative stress response, genes associated with Parkinson's disease and inflammatory pathways. Drug Chem Toxicol 1-8. https://doi.org/10.1080/01480545.2018.1504961

20. Farombi EO, Awogbindin IO, Farombi TH, Oladele JO, Izomoh ER, Aladelokun OB, Ezekiel IO, Adebambo O I, Abah VO (2019) Neuroprotective role of kolaviron in striatal redo-inflammation associated with rotenone model of Parkinson's disease. NeuroToxicol 73:132-141. https://doi.org/10.1016/j.neuro.2019.03.005

21. Garabadu D, Agrawal N (2020). Naringenin exhibits neuroprotection against rotenone-induced neurotoxicity in experimental rodents. Neuromol Med. http://doi.org.10.1007/s12017-019-08590-2.

22. Garcia-Sánchez A, Miranda-Diaz AG, Cadona-Muňoz EG, (2020) The role of oxidative stress in physiopathology and pharmacological treatment with pro- and antioxidant properties in chronic diseases. Oxid Med Cell Longev 2082145. https://doi.org/10.1155/2020/2082145

23. Goldstein DS, Sullivan P, Cooney A, Jinsmaa Y, Kopin IJ, Sharabi Y (2015) Rotenone decreases intracellular aldehyde dehyrogenase activity: implications for the pathogenesis of Parkinson's diseases . J Neuro Chem 356:483-92. https://doi.org/10.1111/jnc. 13042

24. Guevara, I., Iwanejko, J., Dembińska-Kieć, A., Pankiewicz, J., Wanat, A., Anna, P., Gołabek, I., Bartuś, S., Malczewska-Malec M, Szczudlik A (1998) Determination of nitrite/nitrate in human biological material by the simple Griess reaction. Clin Chim Acta 274:177-188. https://doi.org/10.1016/s00098981(98)00060-6

25. Guo L, Zhang Y, Li Q (2009) Spectrophotometric determination of dopamine hydrochloride in pharmaceutical, banana, urine and serum samples by potassium ferricyanide-Fe(III). Anal Sci 25:1451-1455. https://doi.org/10.2116/analsci.25.1451

26. Haque R, Bin-Hafeez B, Parvez S, Pandey S, Sayeed I, Ali M, Raisuddin S (2003) Aqueous extract of walnut (Juglans regia L.) protects mice against cyclophosphamide-induced biochemical toxicity. Hum Exp Toxicol 22:473-480. https://doi.org/10.1191/0960327103ht388oa

27. Hasanuzzaman M, Bhuyan MHMB, Zulfiqar F, Raza A, Mohsin SM, Mahmud JA, Fujita M, Fotopoulos V (2020) Reactive oxygen species and antioxidant defense in plants under abiotic stress: revisiting 
the crucial role of a universal defense regulator. Antioxidants 9(8):681.

https://doi.org/10.3390/antiox908068

28. Inoue T, Saito S, Tanaka M, Yamakage H, Kusakabe T, Shimatsu A, Ihara M, Satoh-Asahara N (2019) Pleiotropic neuroprotective effects of taxifolin in cerebral amyloid angiopathy. PNAS 116(20):1003110038. https://doi.org/10.1073/pnas.1901659116

29. Jia Z, Anandha Babu PV, Chen W, Sun X (2018) Natural products targeting on oxidative stress and inflammation: mechanisms, therapies and safety assessment. Oxid Med Cell Longev 6576093. https://doi.org/10.1155/2018/6576093

30. Kakkar P, Das B ,Viswanathan PN (1984) A modified spectrophotometric assay of superoxide dismutase. Indian J Biochem Biophys 21(2):130-132

31. Khadrawy YA, Salem AM, El-Shamy KA, Ahmed EK, Fadl NN, Hosny EN (2017) Neuroprotective and therapeutic effect of caffeine on the rat model of Parkinson's disease induced by rotenone. J Diet Suppl https://doi.org/10.1080/19390211.2016.1275916

32. Kanki R, Nakamizo T, Yamashita H, Kihara T, Sawada H, Uemura K, Kawamataa J, Shibasaki H, Akaike A, Shimohama S (2004) Effects of mitochondrial dysfunction on glutamate receptormediated neurotoxicity in cultured rat spinal motor neurons. Brain Research, 1015(1-2), 73-81. https://doi.org/10.1016/j.brainres.2004.04.044

33. Korhonen R, Lahti A, Kankaanranta H, Moilanen E (2005) Nitric oxide production and signaling inflammation. Curr Drug Targets Inflamm Allergy 4(4):471-

479. https://doi.org/10.2174/1568010054526359

34. Krajewski WW, Collins R, Holmberg-Schiavone L, Jones TA, Karlberg T, Mowbray SL (2008) Crystal structures of mammalian glutamine synthetases illustrate substrate-induced conformational changes and provide opportunities for drug and herbicide design. J Mol Biol 375:217-228. https://doi.org/10.2210/pdb2ojw/pdb

35. Liang L, Gao C, Luo M, Wang W, Zhao C, Zu Y, Efferth T, Fu Y (2013) Dihydroquercetin induced HO-1 and NQ01 expression against oxidative stress through the Nrf2-dependent antioxidant pathway. J Agric Food Chem 61(11):2755-2761. https://doi.org/10.1021/jf304768p

36. Liu H, Zhu X, Weng E (2005) Intracellular dopamine oxidation mediates rotenone-induced apoptosis in PC12 cells. Acta Pharmacol Sin 26(1):17-26. https://doi.org/10.1111/j.1745-7254.2005.00003.x

37. Ma J, Gao SS, Yang HJ, Wang M, Cheng BF, Feng ZW, Wang L (2018) Neuroprotective effects of proanthocyanidins, natural flavonoids derived from plants, on rotenone-induced oxidative stress and apoptotic cell death in human neuroblastoma SH-SY5Y cells. Front Neurosci 12:369. https://doi.org/10.3389/fnins.2018.00369

38. Mohapatra S, Prasad A, Haque F, Ray S, De B, Ray SS (2015) In silico investigation of black tea components on a-amylase, a-glucosidase and lipase. J Appl Pharm Sci 5(12):42-47. http://doi.org/10.7324/JAPS.2015.501207

39. Nakashima A, Ota A, Kaneko YS, Mori K, Nagasaki H, Nagatsu T (2013) A possible pathophysiological role of tyrosine hydroxylase in Parkinson's disease suggested by post mortem 
brain biochemistry: a contribution for the special $70^{\text {th }}$ birthday symposium in honour of Prof. Peter Riederer. J Neural Transm 120(1):49-54. https://doi.org/10.1007/s00702-012-0828-5

40. Ogunwa TH, Ayenitaju FC (2017) Molecular binding signatures of morelloflavone and its naturally occurring derivatives on HMG-COA reductase. Int J Biol Sci Applic 4(5):74-81.

41. Parveen Z, Nawaz MZ, Shakil S, Greig NH, Kamal MA (2012) Molecular Docking Study of Catecholamines and [4-(Propan-2-yl) Phenyl]Carbamic acid with Tyrosine Hydroxylase. CNS Neurol. Disord Drug Targets 11(4): 463-468. https:// doi.org/10.2174/187152712800792884

42. Paunkov A, Chartoumpekis DV, Ziros PG, Sykiotis GP (2019) A bibliometric review of Keap1/Nrf2 pathway and its related antioxidant compounds. Antioxidants 8(9):353. https://doi.org/10.3390/antiox8090353.

43. Phan MAT, Paterson J, Bucknall M, Arcot J (2018). Interactions between phytochemicals from fruits and vegetables: Effects on bioactivities and bioavailability. Crit Rev Food Sci Nutr 58(8):1310-1329. https://doi.org/10.1080/10408398.2016.1254595

44. Prajda N, Weber G (1975) Malignant transformation-linked imbalance: decreased xanthine oxidase activity in hepatomas. Fed Eur Biochem Soc Lett 59(2):245-249. https://doi.org/10.1016/00145793(75)80385-1

45. Procházková D, Boušová I, Wilhelmová N (2011) Antioxidant and prooxidant properties of flavonoids. Fitoterapia 82(4):513-523. https://doi.org/10.1016/j.fitote.2011.01.018

46. Razak S, Afsar T, Ulla A, Almajwal A, Alkholief M, Alshamsan A, Jahan S (2018) Taxifolin, a natural flavonoid interacts with cell cycle regulators causes cell cycle arrest and causes tumor regression by activating Wnt/ $\beta$-catenin signaling pathway. BMC Cancer 18:1043. https://doi.org/10.1186/s12885018-4959-4

47. Sai Y, Zhen J, Wu Q, Liu H, Zho J, Dong Z (2008). Phosphorylated ERK $1 \frac{1}{2}$ and neuronal degeneration induced by otenone in hippocampus neuron. Environ Toxicol Pharmacol 27:366-372. https://doi.org/10.1016/j.etap.2008.12.004.

48. Saliu IO, Amoo ZA, Khan MF, Olaleye MT, Rema V, Akinmoladun AC (2020) Abatement of neurobehavioral and neurochemical dysfunctions in cerebral ischemia/reperfusion injury by Tetrapleura tetraptera fruit extract. J Ethnopharm 264. https://doi.org/10.1016/j.jep.2020.113284

49. Sandoval-Avila S, Diaz NF, Gómez-Pinedo U, Canales-Aguirre AA, Gutiérrez-Mercado YK, PadillaCamberos E, Marquez-Aguirre AL, Díaz-Martínez NE (2019) Neuroprotective effects of phytochemicals on dopaminergic neuron cultures. Neurología (English Edition) 34(2):114-124. https://doi.org/10.1016/j.nrleng.2016.04.014

50. Schneider CB, Donix M, Linse K, Werner A, Fauser M, Klingelhoefer L, Lohle M, von Kummer R,Reichmann H, Storch A (2017) Accelerated Age-Dependent Hippocampal Volume Loss inParkinson Diseasewith Mild Cognitive Impairment. Am J Alzheimers Dis Other Demen 32:313-319. https://doi.org/10.1177/1533317517698794

51. Shinoda T, Ogawa H, Cornelius F, Toyoshima C (2009) Crystal structure of the sodium-potassium pump at $2.4 A^{\circ}$ resolution. Nature 459:446-450. http://doi.org/10.1038/nature07939 
52. Son S-Y, Ma J, Kondou Y, Yoshimura M, Yamashita, E., Tsukihara T (2008) Structure of human monoamine oxidase $A$ at $2.2-\AA \AA$ resolution: The control of opening the entry for substrates/inhibitors. PNAS 105:5739-5744. http://doi.org/10.1073/pnas.0710626105.

53. Stanimirovic DB, Ball R, Small DL, Muruganandam A (1999) Developmental regulation of glutamate transporters and glutamine synthetase activity in astrocyte cultures differentiated in vitro. Int $\mathrm{J}$ Dev Neurosci 17:173-184. https://doi.org/10.1016/s0736-5748(99)00028-3

54. Stojanovi DS, Zari D (2009) Hydrogen bonds and hydrophobic interactions of porphyrins in porphyrin containing proteins. Open Struct Biol J 3:34-41. http://doi.org/10.2174/1874199100903010034

55. Svoboda P, Mosinger B (1981) Catecholamines and the brain microsomal Na, Kadenosinetriphosphatase-I protection against lipoperoxidative damage. Biochem Pharmacol 30:427432. https://doi.org/10.1016/0006-2952(81)90626-2

56. Tamilselvam K, Braidy N, Manivasagam M, Essa MM, Prasad WR, Karthikeyan S, Thenmozhi AJ, Selvaraju S, Guillemin GJ (2013) Neuroprotective effects of hesperidin, a plant flavanone, on rotenone-induced oxidative stress and apoptosis in a cellular model for Parkinson's disease. Oxid Med Cell Longev 2013:102741. https://doi.org/10.1155/2013/102741

57. Tanaka M, Saito S, Inoue T, Satoh-Asahara N, Ihara M (2019) Novel Therapeutic Potentials of taxifolin for amyloid- $\beta$-associated neurodegenerative diseases and other diseases: recent advances and future perspectives. Int J Mol Sci 20:2139. https://doi.org/10.3390/ijms20092139

58. Thiffault C, Langston JW, Di Monte DA (2000) Increased striatal dopamine turnover following acute administration of rotenone to mice. Brain Res 885:283-288. https://doi.org/10.1016/s00068993(00)02960-7

59. Tienhaara R, Meany JE (1973) The lactate dehydrogenase catalyzed reduction of pyruvate. Active substrate and substrate inhibition. Biochemistry 12:2067-2070. https://doi.org/10.1021/bi00735a007

60. Trott O, Olson AJ (2010) AutoDock Vina: improving the speed and accuracy of docking with a new scoring function, efficient optimization, and multithreading. J Comput Chem 31:455-461. https://doi.org/10.1002/jcc.21334.

61. Umar HI, Ajayi A, Josiah SS, Saliu T, Danjuma JB, Chukwuemeka PO (2020) In silico molecular docking of selected polyphenols against interleukin-17A target in gouty arthritis. Eur J Biol Res 10(4):352-367. http://doi.org/10.5281/zenodo.4064236

62. Varshney R, Kale RK (1990) Effects of calmodulin antagonists on radiation-induced lipid peroxidation in microsomes. Int J Radiat Biol 58:733-743.

https://doi.org/10.1080/09553009014552121

63. Wang T-Y, Li Q, Bi K-S (2018) Bioactive flavonoids in medicinal plants: Structure, activity and biological fate. Asian J Pharm Sci 13(1):12-23. https://doi.org/10.1016/j.ajps.2017.08.004

64. Weidmann AE (2012) Dihydroquercetin: more than just an impurity? Eur J Pharmacol 684 (1):19-26. https://doi.org/10.1016/j.ejphar.2012.03.035 
65. Yamane T. (1967). Statistics: An introductory analysis (No. HA29 Y2 1967), 2nd Ed., New York: Harper and Row.

66. Yarmohammadi F Hayes AW, Najafi N, Karimi G (2020). The protective effect of natural compounds against rotenone neurotoxicity. J Biochem Mol Toxicol e22605. http://doi.org/10.1002/jbt.22605

67. Zhou Q, Chen B, Wang X, Wu L, Yang Y, Cheng X, Hu Z, Cai X, Yang J, Sun X, Lu W, Yan H, Chen J, Ye J, Sen J, Cao P (2016) Sulforaphane protects against rotenone-induced neurotoxicity in vivo: involvement of the mTOR, Nrf2 and autophagy pathways. Sci Rep 6:32206.

http://doi.org.10.1038/srep32206

Figures

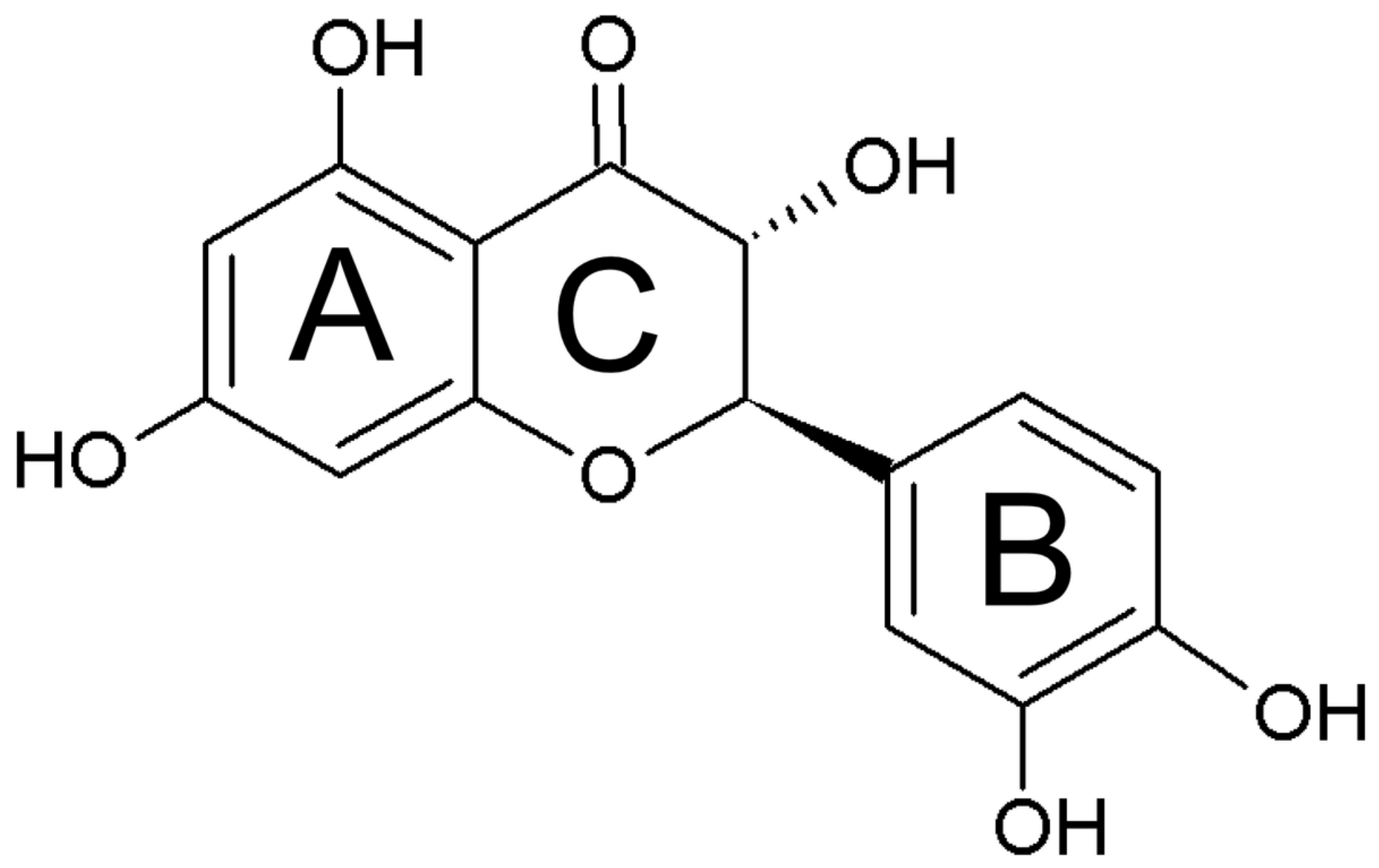

Figure 1

Chemical structure depiction of taxifolin (PubChem ID: 439533) 
(a)
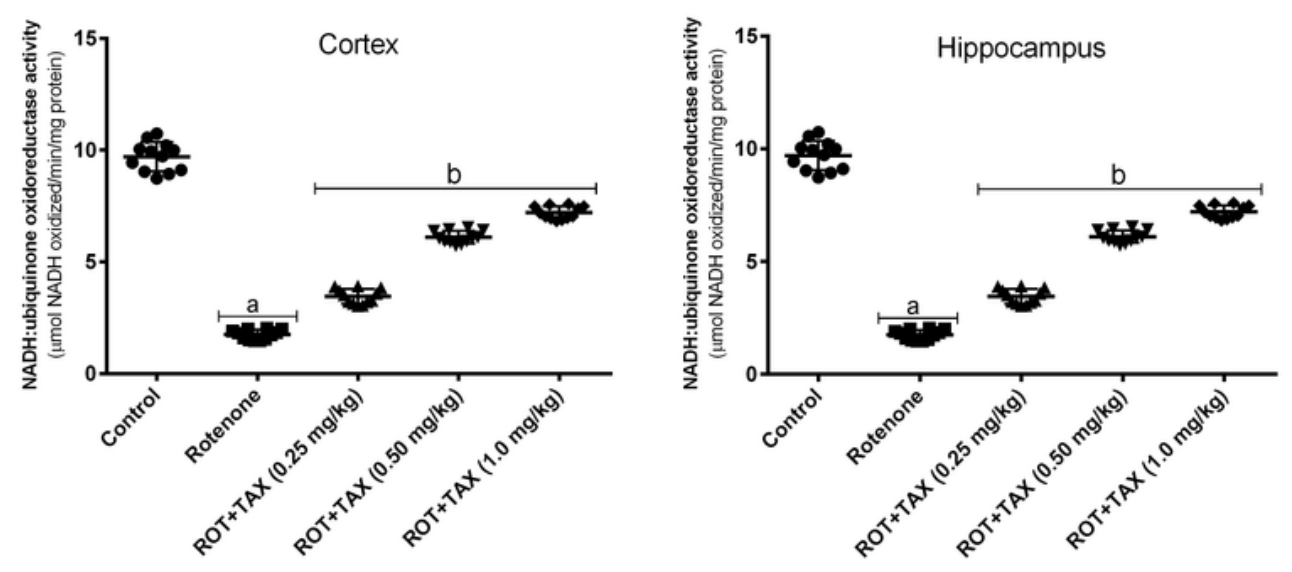

(b)
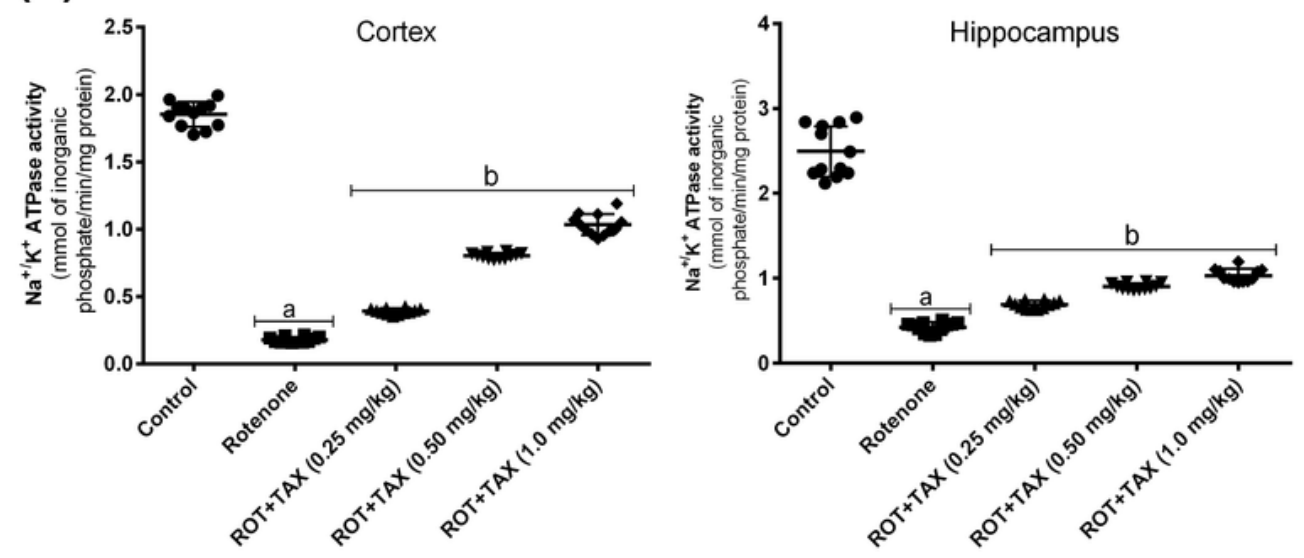

(c)
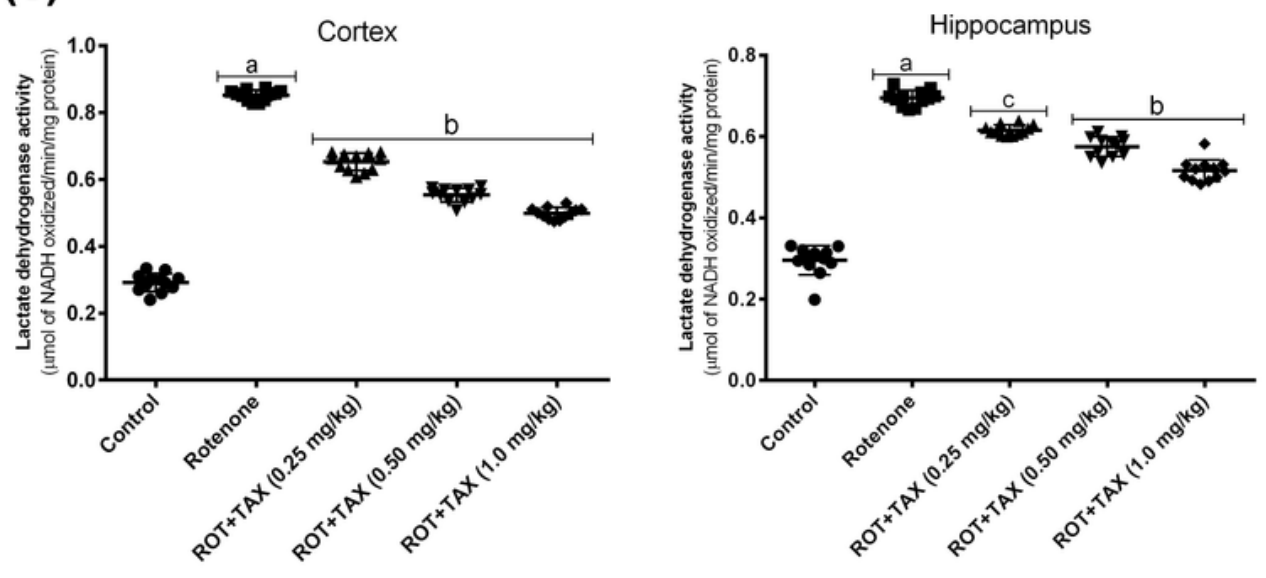

\section{Figure 2}

Effect of taxifolin on mitochondrial and neurochemical dysfunction in the hippocampal and cortical regions of brain of rotenone-toxified rats. (a) Complex I (NADH:Ubiquinone oxidoreductase) activity; (b) $\mathrm{Na}+/ \mathrm{K}+$ ATPase activity; (c) lactate dehydrogenase (LDH) activity. Data are reported as mean \pm standard deviation of the mean (SD) of twelve animals per group (one-way analysis of variance/Tukey's test). Bars with letter ' $a$ ' are significantly different at $p<0.0001$ vs control. Bars with letter 'b and c' are significantly 
different at $p<0.0001$ and $p<0.001$ vs rotenone, respectively. Control: rats only received corn oil as vehicle; Rotenone: rats administered with rotenone for 10 days; ROT + TAX $(0.25,0.5,1.0 \mathrm{mg} / \mathrm{kg})$ : rats administered with rotenone for 10 days followed by 3 -days post-treatment with taxifolin $(0.25,0.5,1.0$ $\mathrm{mg} / \mathrm{kg})$; ROT: Rotenone

(a)
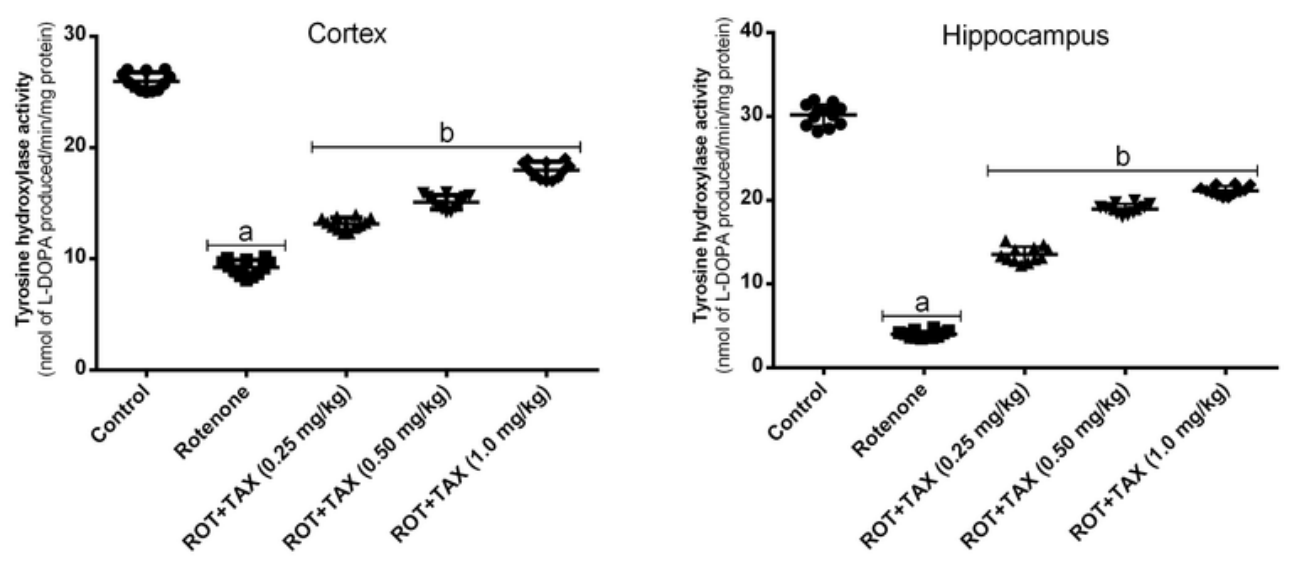

(b)
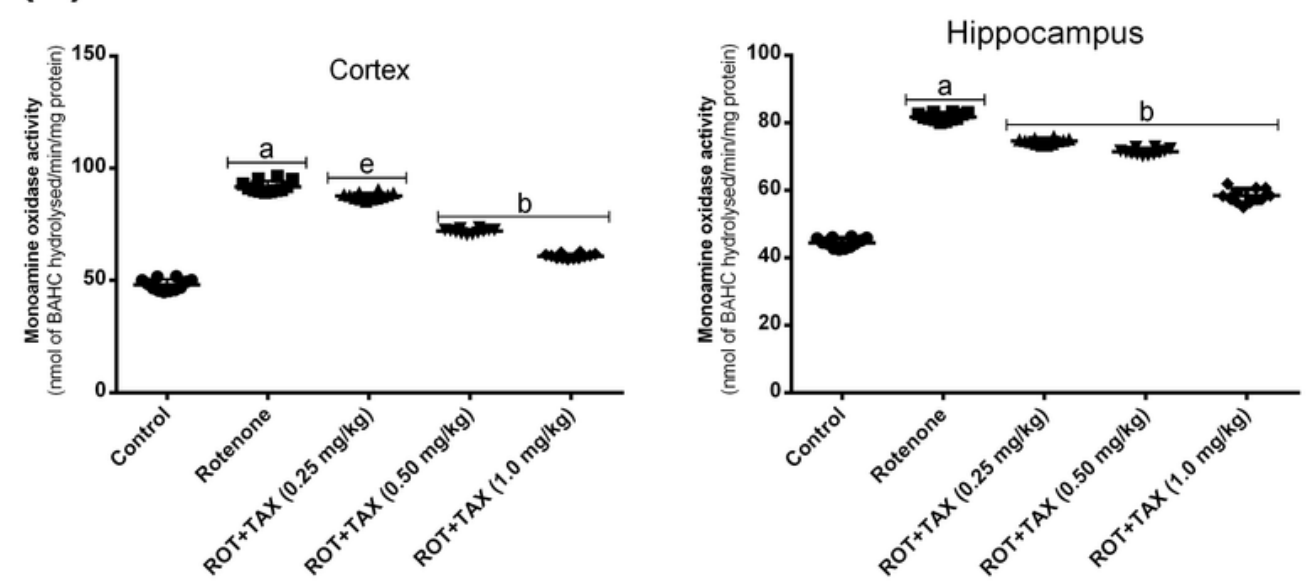

(c)
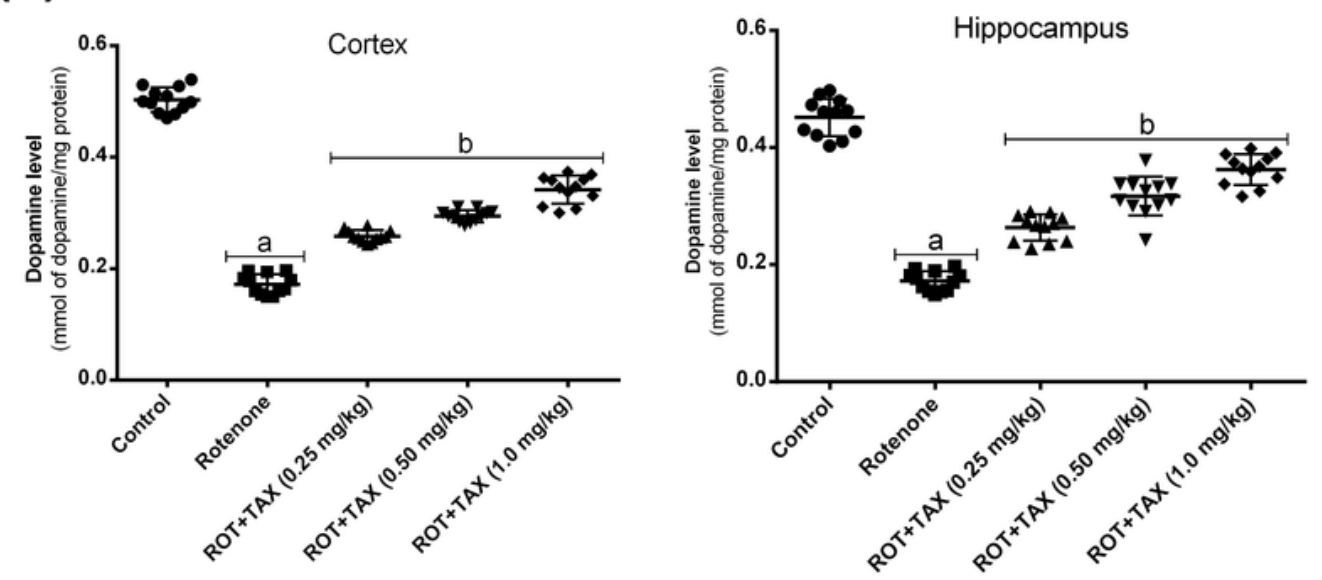

Figure 3 
Effect of taxifolin on dopamine metabolism in the cortical and hippocampal region of brain of rotenonetoxified rats. (a) Tyrosine hydroxylase (TH) activity; (b) Monoamine oxidase (MAO) activity; (c) Dopamine level. Data are reported as mean \pm standard deviation of the mean (SD) of twelve animals per group (oneway analysis of variance/Tukey's test). Bars with letter 'a' are significantly different $p<0.0001$ vs control. Bars with letter ' $b$ ' and ' $e$ ' are significantly different at $p<0.0001$ and $p<0.05$ vs rotenone, respectively. Control: rats only received corn oil as vehicle; Rotenone: rats administered with rotenone for 10 days; ROT $+\operatorname{TAX}(0.25,0.5,1.0 \mathrm{mg} / \mathrm{kg})$ : rats administered with rotenone for 10 days followed by 3-days posttreatment with taxifolin $(0.25,0.5,1.0 \mathrm{mg} / \mathrm{kg}) ; \mathrm{ROT}$ : Rotenone
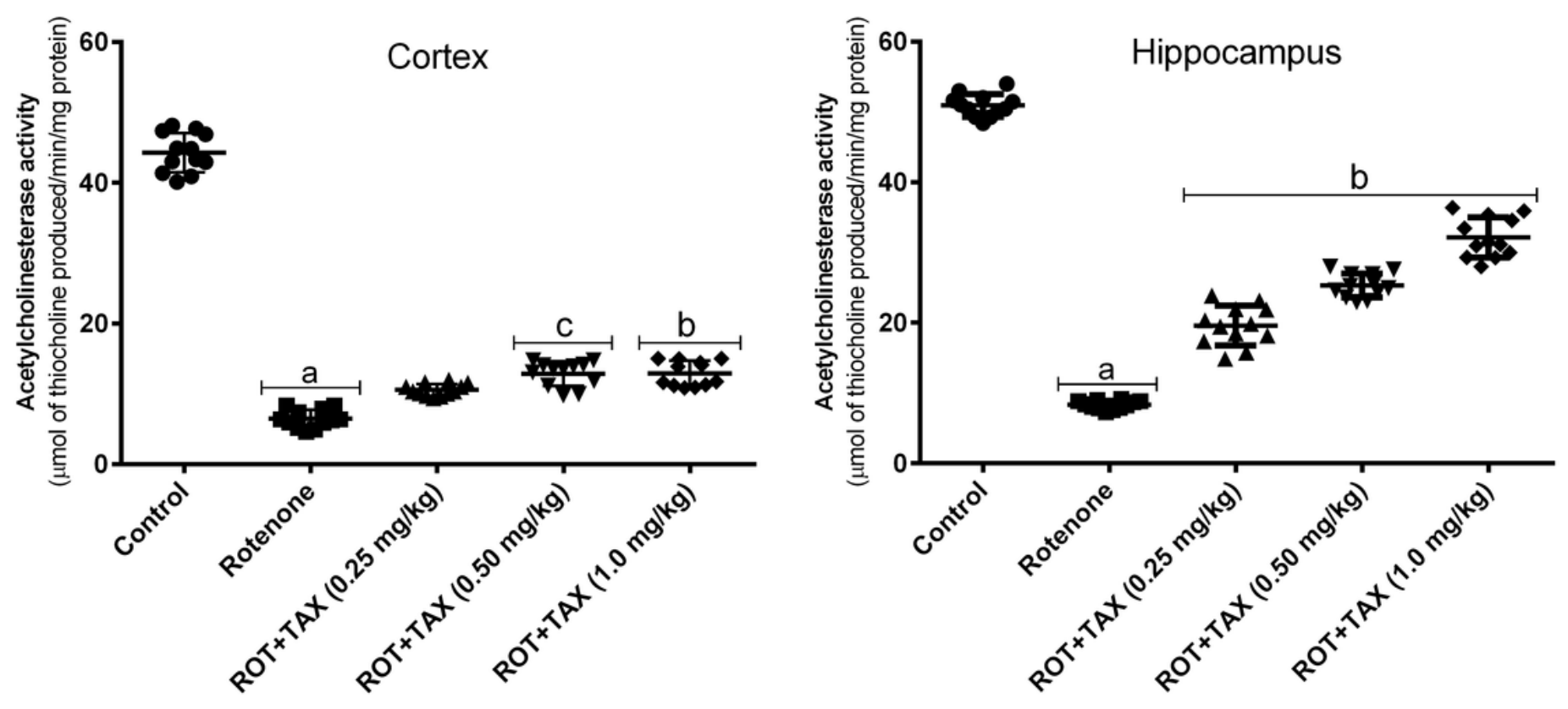

\section{Figure 4}

Effect of taxifolin on acetylcholinesterase (AChE) activity in the cortical and hippocampal region of brain of rotenone-toxified rats. Data are reported as mean \pm standard deviation of the mean (SD) of twelve animals per group (one-way analysis of variance/Tukey's test). Bars with letter 'a' are significantly different at $p<0.0001$ vs control. Bars with letter 'b and $c$ ' are significantly different at $p<0.0001$ and $p<$ 0.001 vs rotenone, respectively. Control: rats only received corn oil as vehicle; Rotenone: rats administered with rotenone for 10 days; ROT + TAX $(0.25,0.5,1.0 \mathrm{mg} / \mathrm{kg})$ : rats administered with rotenone for 10 days followed by 3-days post-treatment with taxifolin $(0.25,0.5,1.0 \mathrm{mg} / \mathrm{kg})$; ROT: Rotenone 


\section{(a)}

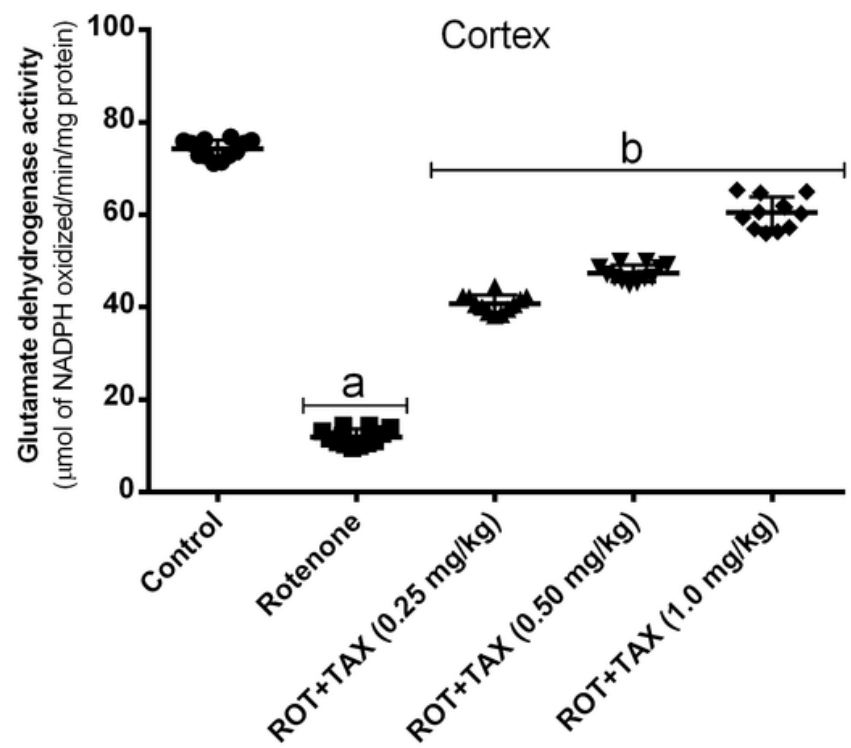

(b)

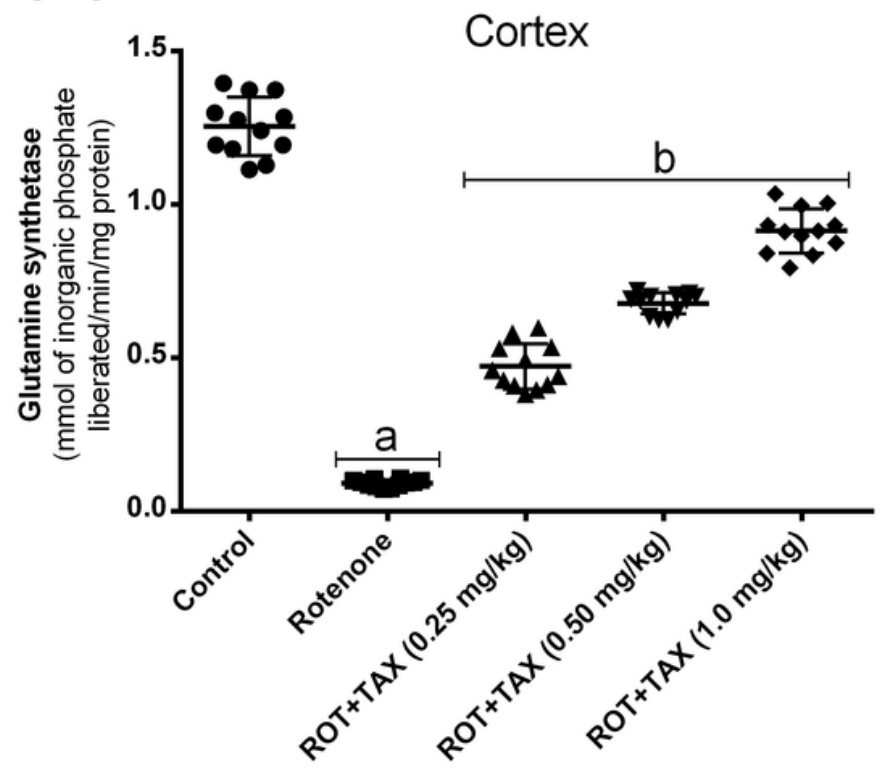

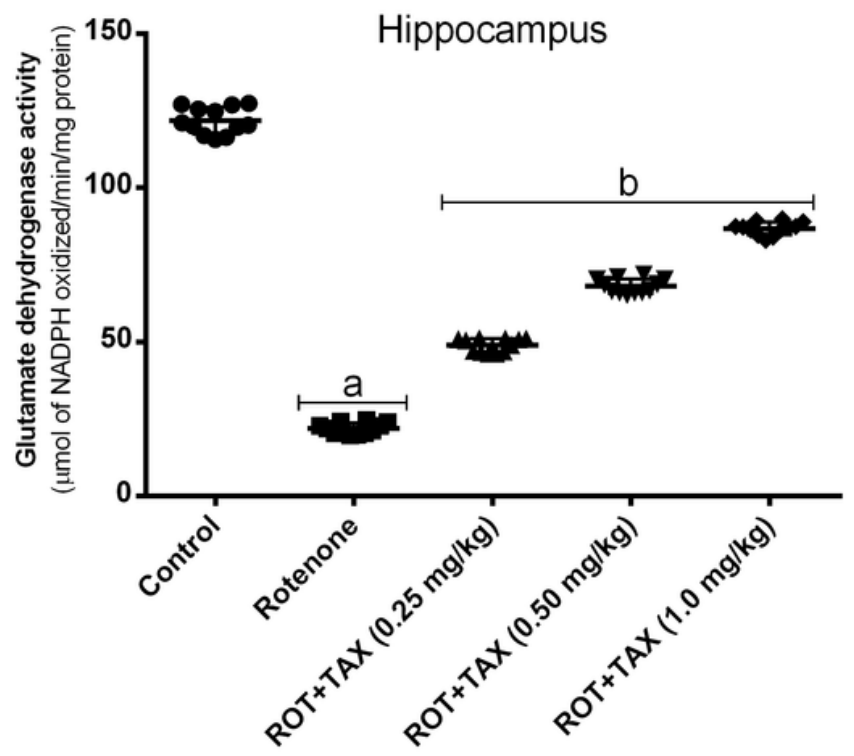

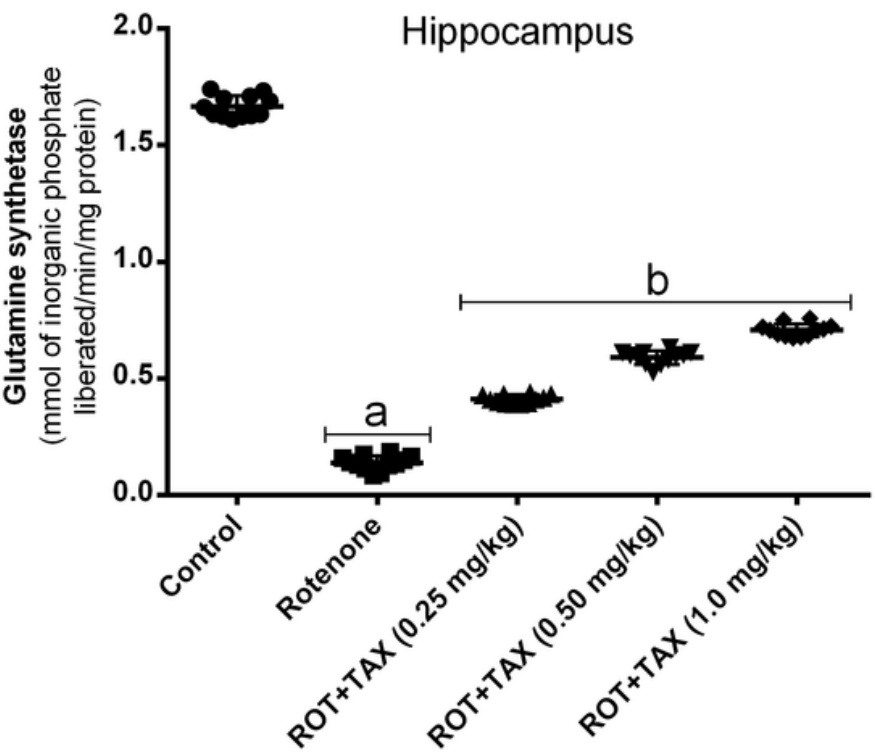

\section{Figure 5}

Effect of taxifolin on glutamate clearance in the cortical and hippocampal region of brain of rotenonetoxified rats. (a) Glutamate dehydrogenase (GDH) activity; (b) Glutamine synthetase (GS) activity. Data are reported as mean \pm standard deviation of the mean (SD) of twelve animals per group (one-way analysis of variance/Tukey's test). Bars with letter 'a' are significantly different at $p<0.0001$ vs control. Bars with letter ' $b$ ' are significantly different at $p<0.0001$ vs rotenone. Control: rats only received corn oil as vehicle; Rotenone: rats administered with rotenone for 10 days; ROT + TAX $(0.25,0.5,1.0 \mathrm{mg} / \mathrm{kg})$ : rats administered with rotenone for 10 days followed by 3 -days post-treatment with taxifolin $(0.25,0.5,1.0$ $\mathrm{mg} / \mathrm{kg}) ;$ ROT: Rotenone 
(a)
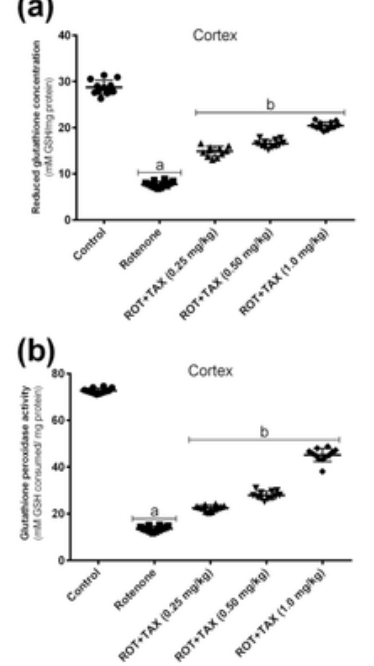

(c)

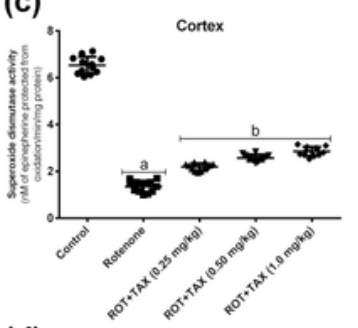

(d)
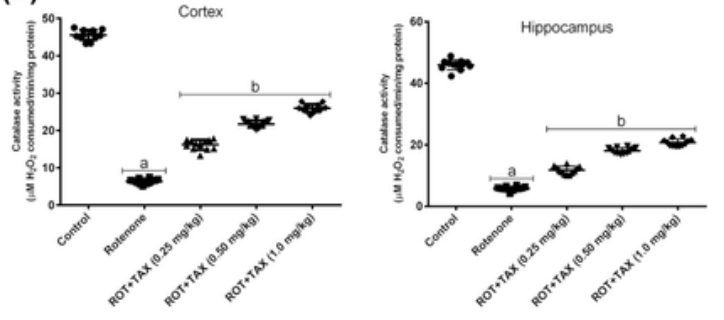

(i)

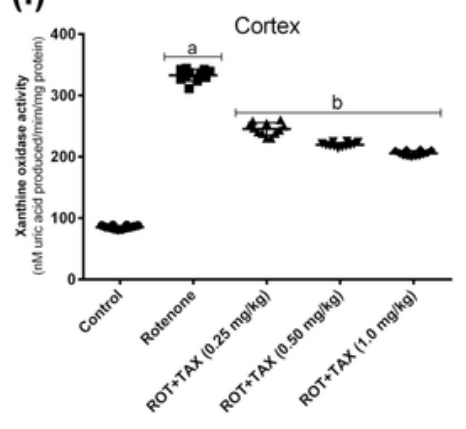

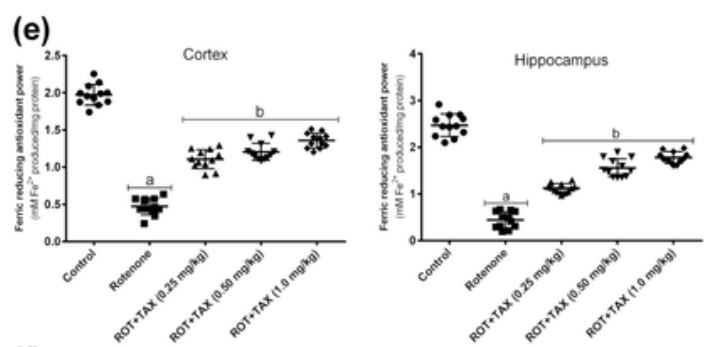

(f)
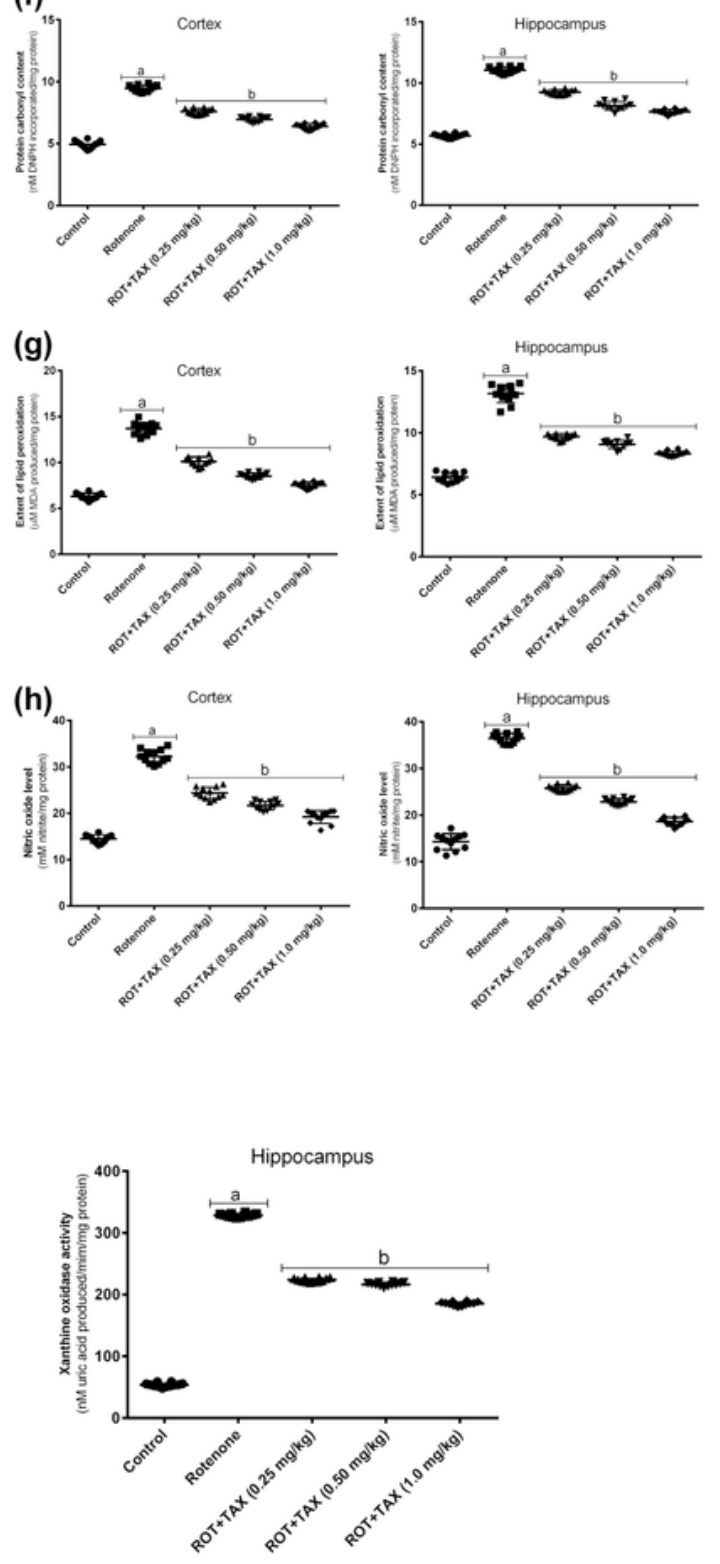

\section{Figure 6}

Effect of taxifolin on oxidative stress markers in the cortical and hippocampal region of brain of rotenone-toxified rats. (a) Reduced glutathione (GSH) activity; (b) Glutathione peroxidase (GPx) activity; (c) Superoxide dismutase (SOD) activity; (d) Catalase activity; (e) Ferric reducing antioxidant power (FRAP) level; (f) Protein carbonyl level; (g) Lipid peroxidation (TBARS); (h) Nitric oxide (NO) level. (i) Xanthine oxidase $(\mathrm{XO})$ activity. Data are reported as mean \pm standard deviation of the mean (SD) of 
twelve animals per group (one-way analysis of variance/Tukey's test). Bars with letter 'a' are significantly different $p<0.0001$ vs control. Bars with letter ' $b$ ' and ' $e$ ' are significantly different at $p<0.0001$ and $p<$ 0.05 vs rotenone, respectively. Control: rats only received corn oil as vehicle; Rotenone: rats administered with rotenone for 10 days; ROT + $\operatorname{TAX}(0.25,0.5,1.0 \mathrm{mg} / \mathrm{kg})$ : rats administered with rotenone for 10 days followed by 3-days post-treatment with taxifolin $(0.25,0.5,1.0 \mathrm{mg} / \mathrm{kg})$; ROT: Rotenone.
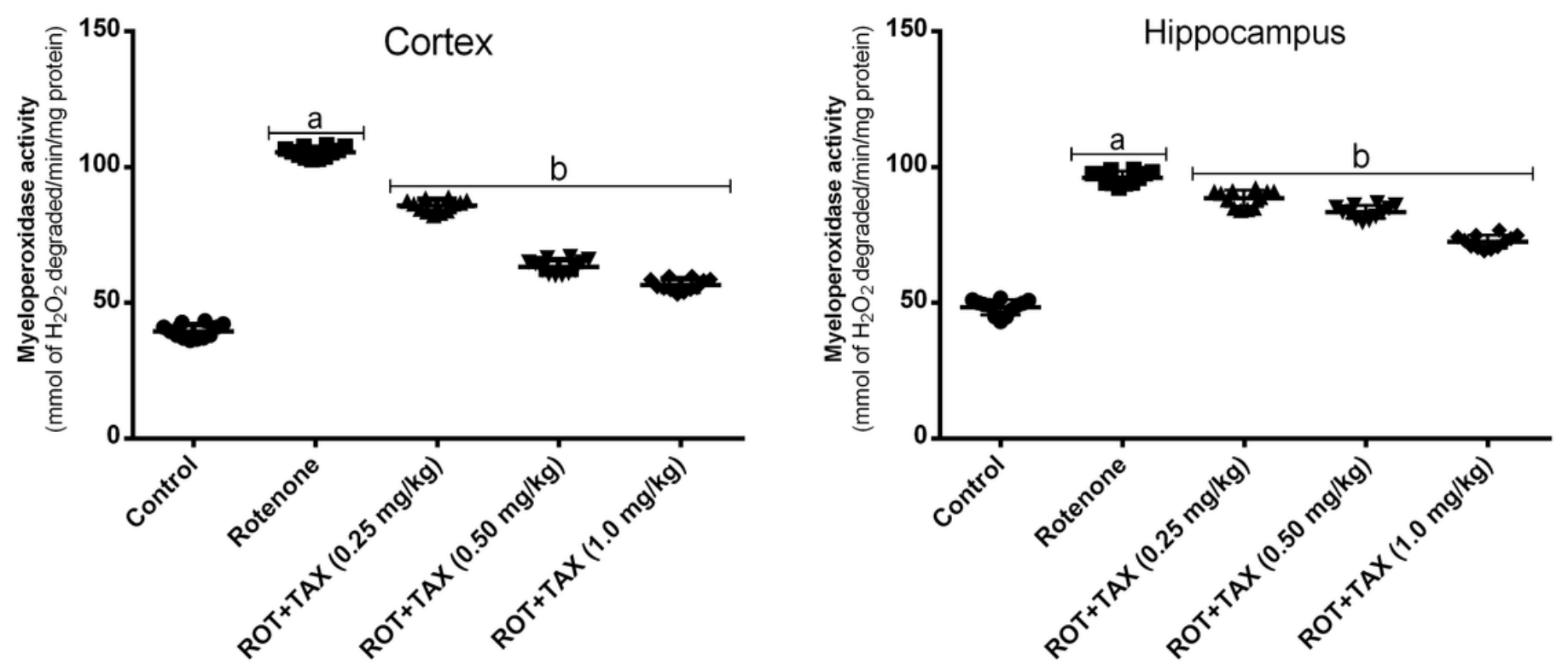

\section{Figure 7}

Effect of taxifolin on myeloperoxidase (MPO) activity in the cortical and hippocampal region of brain of rotenone-toxified rats. Data are reported as mean \pm standard deviation of the mean (SD) of twelve animals per group (one-way analysis of variance/Tukey's test). Bars with letter 'a' are significantly different $p<0.0001$ vs control. Bars with letter ' $b$ ' are significantly different at $p<0.0001$ vs rotenone. Control: rats only received corn oil as vehicle; Rotenone: rats administered with rotenone for 10 days; ROT $+\operatorname{TAX}(0.25,0.5,1.0 \mathrm{mg} / \mathrm{kg})$ : rats administered with rotenone for 10 days followed by 3-days posttreatment with taxifolin $(0.25,0.5,1.0 \mathrm{mg} / \mathrm{kg})$; ROT: Rotenone 

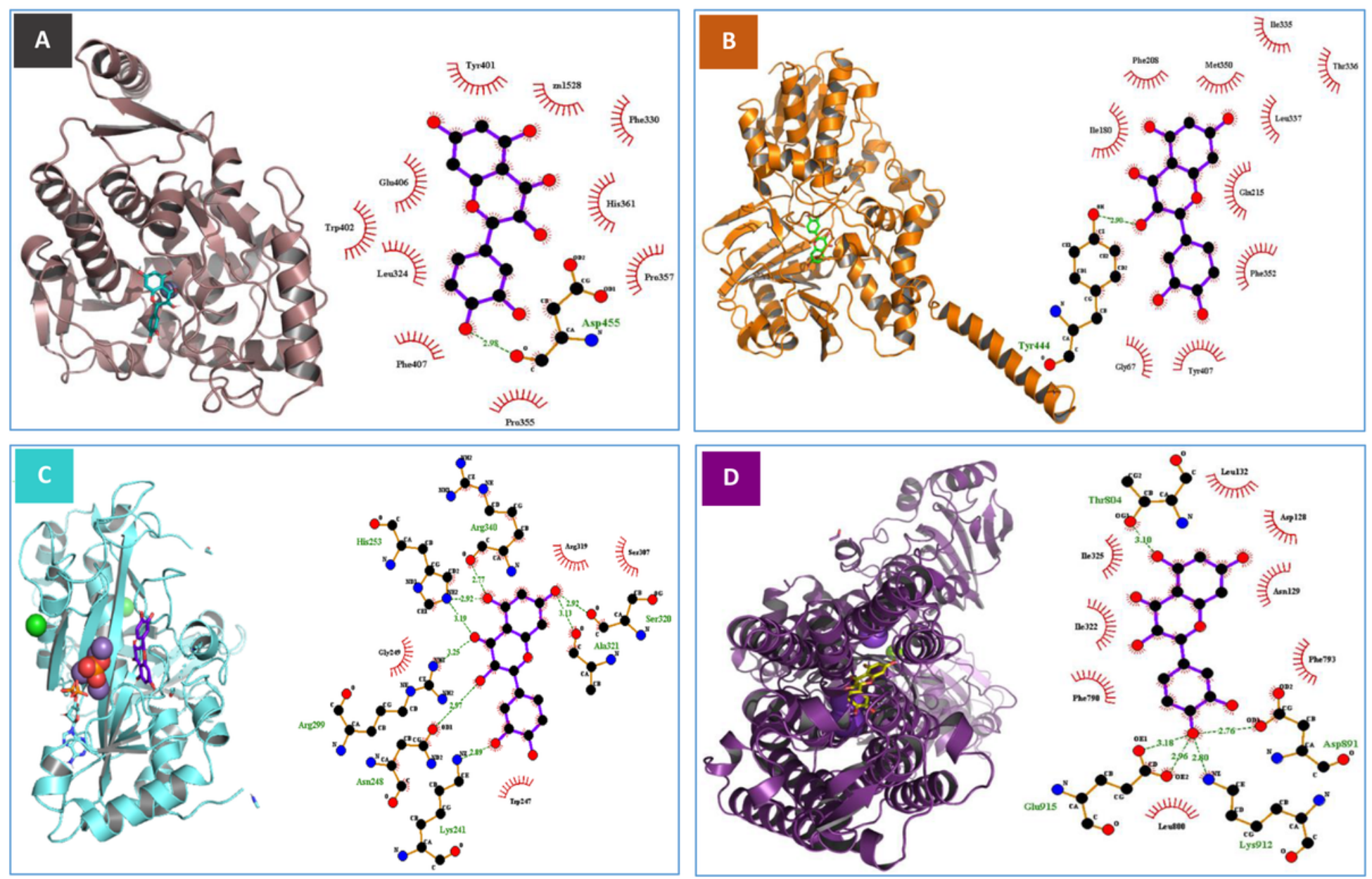

Figure 8

Binding conformation (3D) of taxifolin when docked with some selected enzymes linked to neurotoxicity. (a) Tax-TH complex, TH (brown cartoon) with taxifolin (green) bind to its active site domain and 2D molecular interaction of taxifolin with amino acid residues that reside within the catalytic domain of $\mathrm{TH}$; (b) Tax-MAO complex, MAO (gold cartoon) with taxifolin (green) bind to its active site domain and 2D molecular interaction of taxifolin with amino acid residues that reside within the catalytic domain of MAO; (c) Tax-GS complex, GS (cyan cartoon) with taxifolin (blue) bind to its active site domain and 2D molecular interaction of taxifolin with amino acid residues that reside within the catalytic domain of GS; (d) Tax- $\mathrm{Na}+/ \mathrm{K}+$ ATPase complex, $\mathrm{Na}+/ \mathrm{K}+$ ATPase (purple cartoon) with taxifolin (gold) bind to its active site domain and 2D molecular interaction of taxifolin with amino acid residues that reside within the catalytic domain of $\mathrm{Na}+\mathrm{K}+$ ATPase. Green dashes and red curved spikes in the 2D plots represent hydrogen bonds and hydrophobic interactions, respectively. The molecular docking experiment was executed using auto dock vina, PyMOL and LigPlot software.

\section{Supplementary Files}

This is a list of supplementary files associated with this preprint. Click to download. 
- Supplementarymaterials.docx

Page 30/30 